This is the final peer-reviewed accepted manuscript of:

Roberto Dieci, Frank Westerhoff, Heterogeneous expectations, boom-bust housing cycles, and supply conditions: A nonlinear economic dynamics approach, Journal of Economic Dynamics and Control, Volume 71, 2016, Pages 21-44, ISSN 0165-1889.

The final published version is available online at : https://doi.org/10.1016/j.jedc.2016.07.011.

Rights / License:

The terms and conditions for the reuse of this version of the manuscript are specified in the publishing policy. For all terms of use and more information see the publisher's website.

This item was downloaded from IRIS Università di Bologna (https://cris.unibo.it/)

When citing, please refer to the published version. 


\title{
Heterogeneous expectations, boom-bust housing cycles, and supply conditions: a nonlinear economic dynamics approach
}

\author{
Roberto Dieci ${ }^{\mathrm{a}, \mathrm{b}}$ and Frank Westerhoff ${ }^{\mathrm{c}}$ \\ ${ }^{a}$ Department of Mathematics, University of Bologna, Italy \\ ${ }^{c}$ Department of Economics, University of Bamberg, Germany
}

\begin{abstract}
We combine a standard stock-flow housing market model, incorporating explicit relationships between house prices, the housing stock, and the rent level, with a parsimonious expectation formation scheme of housing market investors, reflecting an evolving mix of extrapolative and regressive expectation rules. The model results in a two-dimensional discrete-time nonlinear dynamical system. Based on realistic parameters, the model is able to generate endogenous boom-bust housing market dynamics with lasting periods of overvaluation and overbuilding. We thus exploit our model to investigate how real forces, in particular supply conditions, interact with expectations-driven housing market fluctuations.
\end{abstract}

\section{Keywords}

Housing markets; Speculation; Housing supply; Boom-bust cycles; Nonlinear dynamics.

\section{JEL classification}

D84; R21; R31.

\footnotetext{
${ }^{\mathrm{b}}$ Corresponding author: Roberto Dieci, University of Bologna, Department of Mathematics, Piazza di Porta San Donato 5, I-40126 Bologna, Italy. Email: roberto.dieci@ unibo.it.
} 


\section{Introduction}

Housing market dynamics may be investigated within theoretical frameworks where agents are fully rational and forward looking. In such perfect-foresight or rational-expectations frameworks, price fluctuations are regarded as temporary adjustments to sequences of exogenous shocks impinging on the fundamentals of the housing market, such as rents, population growth, construction costs, the user cost of capital, etc. (Poterba 1984, 1991, Clayton 1996, Glaeser and Gyourko 2007, Brunnermeier and Julliard 2008). However, this approach is at odds with a number of actual housing market phenomena. For instance, there is evidence against real estate market efficiency (Case and Shiller 1989, 1990) and, in particular, there are boom-bust housing cycles which cannot be explained by changes in economic fundamentals (Wheaton 1999, Shiller 2007).

A large body of economic literature has thus accepted the view that housing market dynamics depend at least partially on some kind of bounded rationality and on the behavioral heterogeneity of housing market investors. Most prominently, Shiller (2005) argues that elements such as optimism and pessimism, herd behavior, and feedback expectations need to be taken into account to model the dynamics of housing markets. Trends in this direction are common to a wide range of research fields broadly related to economics and finance, including behavioral economics (Cutler et al. 1991, Shiller 2008), real estate economics (Wheaton 1999, Malpezzi and Wachter 2005), urban economics (Glaeser et. al 2008), and financial economics (Piazzesi and Schneider 2009, Burnside et al. 2012).

A recurring theme of this strand of literature is the joint impact of the speculative behavior of housing market investors and the real side of housing markets on the dynamics of house prices. ${ }^{1}$ Let us briefly recap a number of central insights on this issue:

\footnotetext{
${ }^{1}$ Of course, there exist also broader macroeconomic issues related to the effects of housing market speculation, such as loose credit conditions or economy-wide effects of housing market crashes (Iacoviello 2005, Adam et al. 2011, Geanakoplos et al. 2012, Favilukis et al. 2013).
} 
(i) Housing is both a consumption good and an investment good. Housing prices thus include a fundamental component, based on the rent level, and a speculative bubble component, based on the price expectations of housing market investors. In this respect, the price-rent ratio is an important indicator of the state of housing market bubbles (Himmelberg et al. 2005, Gallin 2008, Campbell et al. 2009).

(ii) The real side of housing markets (housing durability, supply elasticity, construction lags) differs strongly across housing markets and may interact in different ways with housing market investors' speculative demand (Wheaton 1999, Malpezzi and Wachter 2005).

(iii) Housing markets with a less elastic supply, due to structural and/or institutional constraints, tend to display longer and more pronounced bubbles (Glaeser et al. 2005, 2008, Gyourko 2009, Grimes and Aitken 2010, Paciorek 2013).

(iv) Developers' price expectations, along with development lags, may generate periods with significant overbuilding (Chinloy 1996, Grenadier 1996, Lee 1999, DeCoster and Strange 2012).

(v) The level of overbuilding attained during boom phases is an important factor, along with changes in market sentiments, for the timing and size of crashes (McCue and Belsky 2007, Haughwout et al. 2012).

In recent years, the Bounded Rational Heterogeneous Agent approach (BRHA for short) to the dynamics of speculative markets has been able to contribute to the financial and economic literature in a number of important directions (for surveys, see Chiarella et al. 2009, Hommes and Wagener 2009, Lux 2009). Since BRHA models incorporate in a simple and tractable way the behavioral heterogeneity of agents, they provide plausible qualitative explanations for bubbles and crashes in various types of markets and clear-cut analytical results on how such phenomena may depend on agents' behavioral characteristics. Applied to financial markets, for instance, one of the most popular schemes in the BRHA literature is based on the interaction between chartists and fundamentalists (Day and Huang 1990, 
Chiarella 1992, De Grauwe et al. 1993, Brock and Hommes 1998). Chartists extrapolate past price trends into the future and exert a destabilizing impact on prices. In contrast, fundamentalists expect a mean reversion and act as a stabilizing force. By assuming that their market impact varies endogenously (depending on a variety of behavioral, evolutionary or market factors), their interplay typically results in nonlinear dynamic models with two opposite forces in action, giving rise to complex endogenous price dynamics.

We believe that the BRHA approach may also improve our understanding of the dynamics of housing markets. So far, there has been little effort in this direction, mostly aimed at showing how house prices can fluctuate and deviate substantially from their fundamentals in the presence of heterogeneous investors (Dieci and Westerhoff 2012, 2013), or at estimating the impact of extrapolative beliefs (Eichholtz et al. 2015, Kouwenberg and Zwinkels 2014, Bolt et al. 2014). Our choice of relying on a simple BRHA setup is not just motivated by the goal to provide explanations for bubbles and crashes in housing markets. The ability of BRHA models to generate such kind of dynamics is a well-established result. Instead, by positing that the dynamics of housing markets is at least partially due to the behavior of heterogeneous investors, we seek to understand how behavioral factors and the real side of housing markets jointly influence housing prices and stocks. Put differently, we adopt a simple BRHA model since it can generate expectations-driven cycles very naturally, whilst remaining analytically tractable. It is therefore an ideal setup to address the above discussed issues and to provide clear-cut qualitative insights into how the real side of housing markets interacts with the fluctuations initiated by speculative forces.

Our main findings can be summarized as follows.

(i) Our stock-flow housing market model with perfect-foresight expectations represents a discrete-time generalization of Poterba $(1984,1991)$. The model's unique steady state is either unstable or saddle-path stable. If it is saddle-path stable, a fundamental shock, raising the steady-state coordinates of the house price and the housing stock, causes an immediate 
overshooting of house prices, followed by a monotonic convergence of house prices towards their new steady state and a monotonic correction of the housing stock without overbuilding. This adjustment pattern is qualitatively very similar across a wide range of values for the depreciation rate, the interest rate, the elasticities of the supply of new housing, and the demand for housing services.

(ii) Yet these parameters play a vital role for the dynamics of housing markets under more reasonable backward-looking expectations. Within our BRHA housing market model, a strong extrapolative behavior of housing market investors always destabilizes the model's fundamental steady state, either via a pitchfork bifurcation and the emergence of multiple steady states or via a Neimark-Sacker bifurcation and the appearance of oscillatory dynamics. In particular, the loss of stability may produce very different outcomes depending on the elasticities of the supply of new housing and the demand for housing services. For instance, our analytical and numerical investigation reveals that house price bubbles tend to be shorter under a more elastic supply of new housing or a less elastic demand of housing services. Similarly, a more elastic supply of new housing may result in a significant increase in the housing stock. As we will see, the explanation of such phenomena can be linked directly to our model's bifurcation structures.

(iii) Numerical experiments furthermore suggest that the timing and size of a crash depend on the complex interaction between house prices, the housing stock, and investors' expectations. While repeated downward price adjustments (after a continuous rise) do not necessarily lead to the burst of a bubble, the start of a real crash roughly corresponds to the turning point of the price-rent ratio (which is simultaneously influenced by house prices and the housing stock in our model).

The rest of our paper is organized as follows. In Section 2, we introduce a standard stock-flow housing market framework, based on the interplay between a rental and a (housing) capital market. After deriving the basic model (Section 2.1) and the general steady-state 
properties (Section 2.2), we explore the dynamics under perfect-foresight expectations (Section 2.3) and under backward-looking expectations (Section 2.4). In Section 3, we model expectations of housing market investors as an evolving mix of regressive and extrapolative beliefs. We study analytically how supply and demand elasticities, along with investors' behavioral parameters, jointly impact on the stability of the steady state and on the types of local bifurcations that emerge when speculation becomes stronger. In Section 4, we illustrate the model at work. In Section 4.1, we specify demand and supply curves, establish relationships between their slopes and their elasticities, and identify realistic ranges for the model parameters. In Section 4.2, we simulate the model to assess the joint impact of real and speculative forces on the price dynamics, focusing on the amplitude and duration of housing market bubbles. In Section 4.3, we investigate possible conditions leading to market crashes. Section 5 concludes our paper. A number of analytical results and mathematical details are presented in the Appendix.

\section{A BRHA model based on a stock-flow framework}

In this section, we enrich a well-established stock-flow housing market framework (Poterba 1984, 1991, Wheaton 1999) with a stylized model of boundedly rational housing market investors (Day and Huang 1990, de Grauwe et al. 1993, Brock and Hommes 1998). Section 2.1 outlines the basic stock-flow housing market model. Section 2.2 provides a general discussion of the properties of the model's fundamental steady state as well as its presentvalue representation. Section 2.3 specifies the model to the case of perfect-foresight expectations and performs a steady-state stability analysis of this scenario. Finally, Section 2.4 does the same in the case of fairly general backward-looking expectations.

\subsection{The basic model framework}

According to the traditional stock-flow housing market approach (DiPasquale and Wheaton 
1992), the housing market consists of two interrelated markets: a rental market, i.e. a market for housing services, and a capital market, i.e. a market for housing stock. Given the current housing stock, the demand for housing services determines the rent level (the price of housing services) in the rental market. House prices, in turn, are determined in each period by the demand for housing stock relative to the existing housing stock. The demand for housing stock in the capital market is based on the rent level and expected price appreciation while the housing stock evolves through gradual adjustments depending on housing depreciations and new (price-dependent) housing constructions.

Let us turn to the details of the model. In each period $t$, the flow of housing services $S_{t}$ is proportional to the initial stock of housing $H_{t}$, i.e. $S_{t}=b H_{t}$, with $b>0$. The demand for housing services $D_{t}$ in the same period is a downward-sloped function of the rent level $R_{t}$, i.e. $D_{t}=D\left(R_{t}\right)$, with $D^{\prime}\left(R_{t}\right)<0$. Hence, the market clearing condition for housing services in period $t, D_{t}=S_{t}$, implies that $D\left(R_{t}\right)=b H_{t}$.

Since $R_{t}=D^{-1}\left(b H_{t}\right):=R\left(H_{t}\right)$, with $R^{\prime}\left(H_{t}\right)<0$, the rent level is a decreasing function of the housing stock. ${ }^{2}$

Let us turn to the market for housing capital. A temporary equilibrium condition for price $P_{t}$ of a housing unit (at the beginning of period $t$ ) can be obtained by modeling investors' demand for housing stock within a standard one-period mean-variance framework. Assume that a typical investor faces a wealth allocation problem between housing capital and an alternative riskless asset over the time horizon from $t$ to $t+1$. For a hypothetical housing

\footnotetext{
${ }^{2}$ The law governing housing demand and the rent level is extremely stylized in this model. In reality, exogenous growth factors affecting the population and the demand for housing services may result in an upward trend in rents, even in the event of a growing stock of housing. Stock-flow models can easily be adapted to include such features (Wheaton 1999).
} 
price level $P_{t}$ at time $t$, the investor's end-of-period wealth is

$W_{t+1}=(1+r) W_{t}+H_{t}^{D}\left(P_{t+1}+R\left(H_{t}\right)-(1+r+\delta) P_{t}\right)$,

where $W_{t}$ and $H_{t}^{D}$ are the wealth and the amount of housing units held at the beginning of the period, respectively, and variables indexed with $t+1$ are random. Parameter $\delta>0$ represents the housing depreciation rate, whereas the interest rate $r>0$ includes the return on alternative assets (opportunity cost of capital) and additional costs of owning a house, expressed on a proportional basis (such as property taxes, insurance, etc.). The quantity $r+\delta$ comprises what is called the user cost in the real estate literature (Himmelberg et al. 2005). ${ }^{3}$

Housing market investors seek to maximize the certainty equivalent final wealth. This results in the mean-variance optimization problem $\max _{H_{t}^{D}}\left[E_{t}\left(W_{t+1}\right)-\frac{\lambda}{2} V_{t}\left(W_{t+1}\right)\right]$,

where $E_{t}(\cdot)$ and $V_{t}(\cdot)$ denote investors' conditional expectation and variance, and $\lambda>0$ is the (absolute) risk aversion coefficient. We assume that investors' beliefs about the variance of the end-of-period price (and payoff) are constant over time, i.e. $V_{t}\left(P_{t+1}\right)=\sigma^{2}$. Denoting by $P_{t, t+1}^{e}:=E_{t}\left(P_{t+1}\right)$ the one-period-ahead market expectation of $P_{t+1}$, the solution to the above problem yields

$H_{t}^{D}=H_{t}^{D}\left(P_{t}\right)=\frac{P_{t, t+1}^{e}+R\left(H_{t}\right)-(1+r+\delta) P_{t}}{\lambda \sigma^{2}}$,

by which the investors' optimal demand (amount of housing units) decreases with the current price $P_{t}$ (treated as parametric), given their expectations.

By normalizing the total number of (homogeneous) investors to $N=1$, equilibrium in

\footnotetext{
${ }^{3}$ The user cost may also include a risk premium for owning a house, as well as a component with a negative sign that stands for anticipated (average) capital gains. See Poterba (1992) or Díaz and Luengo-Prado (2008) for detailed discussions of such issues.
} 
the housing market at the beginning of period $t$ results in

$$
H_{t}^{D}:=\frac{P_{t, t+1}^{e}+R\left(H_{t}\right)-(1+r+\delta) P_{t}}{\lambda \sigma^{2}}=H_{t},
$$

where $P_{t}$ now represents the market clearing price.

Equation (2) still holds if the homogeneity assumption is relaxed, provided that $\lambda$ and $\sigma^{2}$ are the same across investors, and $P_{t, t+1}^{e}$ is interpreted as the investors' average price expectation. The assumption of homogeneous and constant second moment beliefs is very common in the heterogeneous-agent literature and made primarily for parsimony and analytical tractability. ${ }^{4}$ In general, models featuring heterogeneous and possibly time varying beliefs about variances and covariances (such as Gaunersdorfer 2000, Chiarella et al. 2006b, 2007) require additional dynamic variables, while not affecting the local stability and bifurcations of the 'fundamental' steady state - which is a major focus of our paper.

The time structure of the model is as follows. First, rent $R_{t}$ is determined at the start of the period based on the current housing stock and equilibrium in the market for housing services (although we assume, for simplicity, that the rent is paid at the end of the period); next, the expectation $P_{t, t+1}^{e}$ of the end-of-period price is formed; finally, based on the (expected) net payoff, the equilibrium price $P_{t}$ is set according to equation (2).

Equation (2) is formally similar to standard asset-pricing equations in one-period mean-variance setups (Brock and Hommes 1998). There are, however, two substantial differences. First, while in financial modeling the supply of assets is typically fixed (or varies exogenously), the housing stock $H_{t}$ evolves endogenously. This raises the question how heterogeneous expectations and speculative house price movements interact with the supply side of the economy. Second, the dividend component of the return, represented here by the

\footnotetext{
${ }^{4}$ Hommes (2013, Ch. 6) briefly discusses this issue and provides a partial justification for this simplifying assumption, based on empirical arguments and results from financial econometrics.
} 
rent, varies endogenously with respect to the housing stock. In asset-pricing models, financial dividends usually are assumed to follow an exogenous noise process.

It is convenient to define a risk-adjusted rent as

$$
\tilde{R}\left(H_{t}\right):=R\left(H_{t}\right)-\lambda \sigma^{2} H_{t} .
$$

In the following, we call $\tilde{R}\left(H_{t}\right)$ also the risk-adjusted inverse demand for housing services. Based on this definition, equation (2) can be rewritten as

$$
(1+r+\delta) P_{t}=P_{t, t+1}^{e}+\widetilde{R}\left(H_{t}\right)
$$

As a limiting case, if investors are risk neutral $(\lambda \rightarrow 0)^{5}$, equation (4) reduces to

$$
P_{t, t+1}^{e}-P_{t}+R\left(H_{t}\right)-\delta P_{t}=r P_{t}
$$

or

$$
P_{t}=\frac{P_{t, t+1}^{e}+R\left(H_{t}\right)}{1+r+\delta}
$$

respectively. ${ }^{6}$

Equation (5) has two straightforward interpretations. A first general interpretation can be given in capital market terms, as the rent can be regarded as the dividend of the housing stock. From this perspective, equation (5) is a no-arbitrage condition, by which the expected net return from investing in housing stock (expected price appreciation plus the rent minus housing depreciation and additional costs) must be equal to the return on alternative assets. As a second interpretation, from the perspective of potential homeowners, equation (5) is essentially an indifference relation between renting and owning a house, where renting a

\footnotetext{
${ }^{5}$ Note that market clearing price $P_{t}$ in equations (2) and (4) can be regarded as a function of $\lambda, P_{t}=P_{t}(\lambda)$. Consistently, housing demand $H_{t}^{D}=H_{t}^{D}(\lambda)$ in equation (2) is identically equal to supply $H_{t}$ for any $\lambda>0$. This identity holds in the limit for $\lambda \rightarrow 0$ as well, as one can easily check.

${ }^{6}$ Lewellen and Shanken (2002) and Branch and Evans (2011) obtain the same standard risk-neutral asset pricing formula in a similar manner as a special case of a mean-variance linear asset pricing model.
} 
housing unit determines a cost of $R\left(H_{t}\right)$ per period, while owning a housing unit has an expected cost of $\delta P_{t}+r P_{t}-\left(P_{t, t+1}^{e}-P_{t}\right)$, that is, depreciation plus foregone interest and additional costs, minus expected appreciation of the housing unit. The second interpretation is peculiar to the housing market and strictly related to the dual nature of housing. In the sequel, we will neglect any additional costs and interpret $r$ simply as the riskless rate of return.

The housing stock evolves according to

$H_{t+1}=(1-\delta) H_{t}+I\left(P_{t}\right)$

where $I\left(P_{t}\right)$ is the (gross) housing investment in period $t$, that is, the amount of new housing constructions. Since our goal is to study the impact of speculative forces on the price dynamics and its interplay with the real part of the economy, we keep the supply side of the housing market model as simple as possible, and merely assume that the amount of new constructions depends positively on the current price, i.e. $I^{\prime}\left(P_{t}\right)>0 .{ }^{7}$ As we will see, $I\left(P_{t}\right)$ and $\widetilde{R}\left(H_{t}\right)$, along with their derivatives, play a prominent role in our model.

Equations (4) and (7) define a discrete-time dynamical system in the house price and housing stock. The dimension and nature of this system depend crucially on how $P_{t, t+1}^{e}$ is specified as a function of future and/or past prices. Nevertheless, it is already possible to extract from this system a number of useful insights about the model's steady-state properties.

\subsection{Fundamental steady state and present-value price-rent relationships}

A steady-state solution $(\bar{P}, \bar{H})$ to dynamical system (4) and (7) necessarily satisfies the

\footnotetext{
${ }^{7}$ A more complete setup should consider the expectations of housing developers at the time building starts and include more general assumptions about development lags. However, it is clear that equation (7) is implicitly based on the assumption of naïve price expectations and a one-period production lag. While this might seem unrealistic at first sight, the real estate literature argues that the house price at the time of the development decision is just as relevant as the expected house price at the delivery date (Wheaton 1999, Barras 2005).
} 
conditions

$\delta \bar{H}=I(\bar{P}), \quad \tilde{R}(\bar{H})+\bar{P}^{e}=(1+r+\delta) \bar{P}$,

where $\bar{P}^{e}$ denotes the price expectation in the steady-state solution path. From the first condition of (8), depreciation exactly offsets the amount of new constructions at the steady state, whereas the second condition imposes market equilibrium with stationary (expected) price and rent levels.

The steady-state price expectation $\bar{P}^{e}$ affects the steady-state price in condition (8). Let us thus define as a fundamental steady state (FSS) $\mathbf{F}:=\left(P^{*}, H^{*}\right)$ a steady-state solution to (8) such that $\bar{P}^{e}=\bar{P}$, that is, expectations are realized at the steady state. It follows that the fundamental price $P^{*}$ is implicitly defined by

$(r+\delta) P^{*}-\tilde{R}\left(I\left(P^{*}\right) / \delta\right)=0$,

while the corresponding stock of housing $H^{*}$ is given by

$H^{*}=I\left(P^{*}\right) / \delta$.

The existence of the FSS is guaranteed under common specifications of functions $R\left(H_{t}\right)$ and $I\left(P_{t}\right)$. Since the left-hand side of (9) is a strictly monotonic function of $P^{*}$, the FSS is necessarily unique.

The fundamental price $P^{*}$ admits a familiar representation in terms of the discounted value of future (risk-adjusted) rents

$P^{*}=\frac{\tilde{R}\left(H^{*}\right)}{r+\delta}$

In addition, equation (11) can be expressed as the price-rent ratio at the FSS

$\pi^{*}:=\frac{P^{*}}{R\left(H^{*}\right)}=\frac{1}{r+\delta+\xi}, \quad \xi=\lambda \sigma^{2} H^{*} / P^{*}$.

The price-rent ratio is a widely adopted measure to quantify mispricings in housing markets 
(Himmelberg et al. 2005). Consistent with the literature, the price-rent ratio $\pi^{*}$ is basically the inverse of the user cost, where the latter possibly includes a risk premium (expressed by quantity $\xi$ in our model). Possible non-fundamental steady states $(\bar{P}, \bar{H})$ such that $\bar{P}^{e} \neq \bar{P}$ do not satisfy the present-value relationships (11)-(12) and may display, for instance, pricerent ratios much larger than $\pi^{*}$.

\subsection{A reference case: perfect foresight}

Before introducing a BRHA model of investors' expectations, it is useful to study the dynamics of model (4) and (7) when investors are rational and forward looking. Perfectforesight expectations imply model-consistent expectations, i.e. $P_{t, t+1}^{e}=P_{t+1}$ for any $t$. Our perfect-foresight model may be regarded as a discrete-time generalization of Poterba (1984, 1991) and its dynamics is due to the two-dimensional nonlinear map

$P_{t+1}=(1+r+\delta) P_{t}-\tilde{R}\left(H_{t}\right)$,

$H_{t+1}=(1-\delta) H_{t}+I\left(P_{t}\right)$,

admitting the FSS $\left(P^{*}, H^{*}\right)$, defined in (9)-(10), as the unique steady state.

The Jacobian matrix at the FSS reads

$\mathbf{J}_{P F}=\left[\begin{array}{cc}1+r+\delta & -\widetilde{R}^{\prime}\left(H^{*}\right) \\ I^{\prime}\left(P^{*}\right) & 1-\delta\end{array}\right]$.

As is common in perfect-foresight models, the FSS is saddle-path stable, provided that, in our case, the product $\left|\tilde{R}^{\prime}\left(H^{*}\right) I^{\prime}\left(P^{*}\right)\right|$ is not too large. More precisely, it turns out that one of the two eigenvalues $z_{1}$ and $z_{2}$ of (15), say $z_{1}$, is positive and larger than one for any selection of the parameters, whereas $0<z_{2}<1$ if and only if the following condition on the economic fundamentals of the housing market holds

$\left|\tilde{R}^{\prime}\left(H^{*}\right) I^{\prime}\left(P^{*}\right)\right|<1+r-\delta(r+\delta)$. 
While one would expect that the dynamics will typically diverge away from the FSS (due to $z_{1}>1$ ), economic arguments impose that the system will move along the saddle path, as briefly illustrated in Figure 1. Moreover, as $0<z_{2}<1$, the dynamics of the housing market along the saddle path is monotonically convergent to the $\mathrm{FSS}^{8}$, although system (13)-(14) cannot be simulated directly under saddle-path stability, in general. Throughout the rest of the paper, we impose a further parameter restriction which implies condition (16), namely $\left|\tilde{R}^{\prime}\left(H^{*}\right) I^{\prime}\left(P^{*}\right)\right|<1, \quad 0<r, \delta<1, \quad r>\delta^{2} /(1-\delta)$, requiring that the risk-adjusted inverse demand for housing services and the new housing supply are not too sloped at the FSS and that the depreciation rate is not too large compared with the interest rate. Under empirically plausible parameter ranges (see section 4.1.3), conditions (17) are largely satisfied.

Given the saddle-path stability property, a 'fundamental' shock changing the coordinates of the FSS triggers a dynamic adjustment process that takes place in a typical, 'well-behaved' manner. Figure 1 sketches the effect of a positive shock to a system that is initially in the FSS $\left(P^{*}, H^{*}\right)$. The shock may, for instance, be caused by an unanticipated and permanent exogenous reduction of the interest rate. Immediately after the shock, both house price and the housing stock find themselves below their new FSS $\left(P^{*}, H^{*}\right)$. This fact sets in motion a sequence of dynamic adjustments by which the price overshoots the new steady state level $P^{*_{1}}$ initially, in order to reach the new saddle path, and then monotonically declines to $P^{* \prime}$ (left panel and top right panel). The housing stock, in turn, increases gradually towards the new steady state level $H^{* \prime}$ (left panel and bottom right panel). Therefore, the convergence

\footnotetext{
${ }^{8}$ Given that $z_{1}>1$, the FSS is saddle-path stable for $-1<z_{2}<1$, which results in the broader condition I $\tilde{R}^{\prime}\left(H^{*}\right) I^{\prime}\left(P^{*}\right) \mid<4+2 r-\delta(r+\delta)$. However, if $-1<z_{2}<0$, the path of each variable is non-monotonic during the convergence to the FSS. We neglect this case in which the discrete-time model behaves so differently to its continuous-time counterpart.
} 
of the economy to the new FSS after a fundamental shock does not involve repeated overshooting and undershooting of the final equilibrium price, nor does it imply overbuilding (with respect to the necessary adjustment of the housing stock). We remark that the qualitative adjustment pattern depicted in Figure 1 remains the same under any parameter setting satisfying condition (16). Furthermore, the dynamic behavior of model (13)-(14) is strongly motivated by economic arguments, which postulate that the system can jump to the new saddle path immediately after the shock, due to the full rationality of housing market investors (see Turnovsky 2000 for an extensive discussion of saddle-path stability in perfect-foresight models). It follows that repeated overshooting or overbuilding phenomena in perfect-foresight models can only occur due to a sequence of exogenous shocks and can by no means be generated endogenously as a result of a unique shock.

*** FIGURE 1 ABOUT HERE ***

\subsection{Backward-looking expectations}

We now turn to a more realistic case in which investors are boundedly rational, heterogeneous and backward looking, forming their expectations through simple heuristics with plausible behavioral interpretations (see Hommes 2013 for an inspiring overview). From this perspective, $P_{t, t+1}^{e}$ can be regarded as the aggregate (or average) market expectation. Concerning the timing of expectation formation and the relevant information set, we assume that $P_{t, t+1}^{e}$ is formed at the beginning of period $t$, based on observations up to period $t-1$ and before the market clearing price $P_{t}$ is determined. Such a time structure is common in the literature; see, for instance, Brock and Hommes (1998).

Throughout this paper, we will adopt the one-lag specification $P_{t, t+1}^{e}=\varphi\left(P_{t-1}\right)$, which allows us to incorporate a behavioral heterogeneity whilst keeping the model to the lowest possible dimension and to perform a complete stability analysis without specifying 
expectation rules in detail. Also, expectations are specified in such a way that $\varphi\left(P^{*}\right)=P^{*}$, which ensures that the FSS $\left(P^{*}, H^{*}\right)$, defined in (9)-(10), is among the (possibly multiple) steady states of the model. Dynamic system (4) and (7) can then be expressed as

$$
\begin{aligned}
& P_{t}=F\left(P_{t-1}, H_{t-1}\right):=\frac{\varphi\left(P_{t-1}\right)+\tilde{R}\left(G\left(P_{t-1}, H_{t-1}\right)\right)}{1+r+\delta}, \\
& H_{t}=G\left(P_{t-1}, H_{t-1}\right):=(1-\delta) H_{t-1}+I\left(P_{t-1}\right),
\end{aligned}
$$

i.e. the model dynamics is again driven by a two-dimensional nonlinear map. ${ }^{9}$

Since $G\left(P^{*}, H^{*}\right)=H^{*}$, the Jacobian matrix of (18)-(19) at the FSS $\left(P^{*}, H^{*}\right)$ reads

$$
\mathbf{J}_{B L}=\left[\begin{array}{cc}
\frac{\varphi^{\prime}\left(P^{*}\right)+\tilde{R}^{\prime}\left(H^{*}\right) I^{\prime}\left(P^{*}\right)}{1+r+\delta} & \frac{(1-\delta) \tilde{R}^{\prime}\left(H^{*}\right)}{1+r+\delta} \\
I^{\prime}\left(P^{*}\right) & 1-\delta
\end{array}\right]
$$

In contrast to the case of perfect foresight, the Jacobian matrix (20) reveals that the local stability of the FSS and the model's long-run dynamics crucially depend on quantity $\varphi^{\prime}\left(P^{*}\right)$, which indicates how reactive the aggregate market expectation is to a price shock locally near the FSS.

To simplify the notation, let us define

$$
\alpha:=-\widetilde{R}^{\prime}\left(H^{*}\right)=-R^{\prime}\left(H^{*}\right)+\lambda \sigma^{2}, \quad \beta:=I^{\prime}\left(P^{*}\right), \quad \gamma:=\varphi^{\prime}\left(P^{*}\right)-1 .
$$

Note that the above quantities depend, in general, on the coordinates of the FSS and therefore on all model parameters. A set of necessary and sufficient conditions (Medio and Lines 2001) for both eigenvalues of (20) to be smaller than one in modulus, which implies a locally asymptotically stable FSS, is given by

$$
1-\operatorname{Tr}+\text { Det }>0, \quad 1+\operatorname{Tr}+\text { Det }>0, \quad 1-\text { Det }>0,
$$

where, with our above notation,

\footnotetext{
${ }^{9}$ An equivalent representation of the model in deviations from the FSS will also be used in the sequel. See Appendix B for its derivation.
} 
$\operatorname{Tr}:=\frac{2+\gamma-\delta-\alpha \beta+(1-\delta)(r+\delta)}{1+r+\delta}$, Det $:=\frac{(1-\delta)(1+\gamma)}{1+r+\delta}$

are the trace and determinant of (20), respectively. The three inequalities in (22) can be rewritten as

$\gamma<r+\delta+\frac{\alpha \beta}{\delta}:=\gamma_{P}, \quad \alpha \beta<(2-\delta)(2+r+\delta+\gamma), \quad \gamma<\frac{r+2 \delta}{1-\delta}:=\gamma_{N S}$,

respectively. ${ }^{10}$

Condition (17) from the perfect-foresight case implies that $0<\alpha \beta, r, \delta<1$. It is reasonable to restrict our analysis to the case $\gamma \geq-1$, i.e. $\varphi^{\prime}\left(P^{*}\right) \geq 0$. This case encompasses a wide range of relevant expectation rules. For instance, if all investors believed in mean reversion to the fundamental price, the market expectation would be expressed as $\varphi\left(P_{t-1}\right)=P_{t-1}+\theta\left(P^{*}-P_{t-1}\right)$. With this specification, condition $\varphi^{\prime}\left(P^{*}\right) \geq 0$ is certainly satisfied under the standard restriction $0<\theta<1$, requiring that predicted mean reversion cannot overshoot the reference price. Alternatively, if all investors believed in the persistence of bull and bear markets, i.e. $\varphi\left(P_{t-1}\right)=P_{t-1}+\mu\left(P_{t-1}-P^{*}\right)$, with $\mu>0$, then $\varphi^{\prime}(P)>1$ (see Section 3 for a fairly general specification of $\varphi(P)$, covering an evolving mix of these two rules). Under these restrictions, the second condition in (24) is obviously always true, and therefore a loss of stability of the FSS may occur if a parameter varies such that the first or third condition is violated.

In Figure 2, we take $\gamma$ and the aggregate quantity $0<A:=\alpha \beta<1$ as bifurcation parameters. The FSS is locally asymptotically stable (LAS henceforth) for any $0<A<1$, if $-1 \leq \gamma<r+\delta$, i.e. $0 \leq \varphi^{\prime}\left(P^{*}\right)<1+r+\delta$. For increasing values of parameter $\gamma$, the FSS may be destabilized if one of the eigenvalues of (20) becomes larger than one. This is the case when the first inequality in (24) becomes violated (while the third inequality holds), which

\footnotetext{
${ }^{10}$ Note that a larger value of the interest rate $r$ at the right-hand side of inequalities (24) results in a wider stability region. From this perspective, a central bank can, at least in principle, stabilize housing markets by increasing the interest rate. Of course, a reduction of the interest rate may destabilize housing markets.
} 
can only occur if $A$ is in the range $(0, \hat{A})$, where $\hat{A}:=\delta^{2}(1+r+\delta) /(1-\delta)$. This case corresponds generically to a fold bifurcation, yet with our particular choice of function $\varphi(P)$ this will result in a pitchfork bifurcation and multiple steady states (see Section 3). Instead, if $\hat{A}<A<1$, an increase of $\gamma$ leads to a loss of stability via a Neimark-Sacker (NS) bifurcation, with two complex conjugate eigenvalues becoming larger than one in modulus. ${ }^{11}$ This is, in fact, what happens if (only) the third inequality in (24) becomes violated. In our experiments (see Section 4), we will find evidence that the NS bifurcation is supercritical and creates a new cyclical attractor surrounding the unstable FSS ('NS scenario'). ${ }^{12}$

Further insights come from identifying the region of the parameter space where the eigenvalues of (20) are complex. As shown in Appendix A, this occurs within the gray shaded region in Figure 2, defined by the inequalities

$(\sqrt{B}-\sqrt{A})^{2}<1+\gamma<(\sqrt{B}+\sqrt{A})^{2}$,

where $A:=\alpha \beta$ and $B:=(1-\delta)(1+r+\delta)$. As shown in Figure 2, the larger $\alpha$ and/or $\beta$, the wider the range of parameter $\gamma$ for which the eigenvalues of $\mathbf{J}_{B L}$ are complex at the FSS.

\section{*** FIGURE 2 ABOUT HERE ***}

In general, nothing can be said at this stage about the precise nature of the local bifurcations and their consequences without specifying functions $\varphi(P), D(R)$, and $I(P)$. However, two important insights emerge from our analysis. First, a sufficiently strong

\footnotetext{
${ }^{11}$ With a fold (or saddle-node) bifurcation, a stable steady state (node) loses its stability via a collision with a coexisting saddle steady state, after which both of them disappear. With a (supercritical) pitchfork bifurcation, a stable node is turned into a saddle with the simultaneous birth of two new stable steady states. With a (supercritical) Neimark-Sacker bifurcation, a stable steady state (focus) becomes unstable and an invariant attracting curve is simultaneously created around it, which brings about periodic or quasiperiodic motion on the curve. For more details see, for instance, Medio and Lines (2001).

12 The ranges of the axes in Figure 2 are chosen such that both bifurcation boundaries can be identified easily. In practice, only the NS bifurcation boundary matters for local bifurcations as the threshold $\hat{A}$ is very low compared to normal ranges of $A:=\alpha \beta$. Therefore, under plausible parameter ranges (Section 4.1.3) we will most likely see the emergence of a NS bifurcation. Nevertheless, the pitchfork bifurcation plays an important role for the model's global dynamics, as will become clear in Section 4.
} 
expectational reaction to the observed mispricing renders the FSS unstable. Second, irrespective of whether the FSS is stable or not, a regime of endogenous oscillations around the FSS (associated with complex eigenvalues) prevails if $A=\alpha \beta$ is large enough, that is, if the slope of the risk-adjusted inverse demand for housing services is sufficiently steep at the FSS and/or if the slope of the supply of new housing is sufficiently steep at the FSS. If $\gamma$ is also large enough and stability is lost, oscillatory dynamics persist in the long run.

\section{The interplay of extrapolative and regressive expectations}

We specify investors' beliefs, predictor selection, and aggregate market expectation in a rather stylized, yet, as we will see, surprisingly powerful way. Investors' beliefs about the price next period rely on a set $H$ of simple predictors, or heuristics. The beliefs of investors of type $h \in H$ are formed according to $P_{t, t+1, h}^{e}=\varphi_{h}\left(P_{t-1}\right):=P_{t-1}+\mu_{h}\left(P_{t-1}-P^{*}\right) \quad$ or, equivalently,

$P_{t, t+1, h}^{e}-P^{*}=\left(1+\mu_{h}\right)\left(P_{t-1}-P^{*}\right)$.

Apparently, parameter $\mu_{h}$ expresses investors' beliefs about the bubble component of house prices. Following Day and Huang (1990), Brock and Hommes (1998), Boswijk et al. (2007), and Westerhoff and Franke (2011), we consider two belief types, namely, regressive expectations (indexed by $h=R$, with $-1<\mu_{R}=-\theta<0$ ), by which investors predict a price correction towards the fundamental price, and extrapolative expectations (indexed by $h=E$, with $\mu_{E}=\gamma>0$ ), by which investors predict an increasing deviation from the fundamental price. $^{13}$

The market impact of these heuristics varies endogenously in the sense that investors

\footnotetext{
13 The extrapolative rule adopted here can be regarded as the limiting case of a moving-average rule, which predicts that the price will grow (decline) if a short-run moving average of past prices is above (below) a longrun moving average (Chiarella et al. 2006a).
} 
tend to switch to regressive expectations as mispricing increases, a feature which introduces stronger mean reversion for large misalignments. This idea of modeling endogenous changes in market sentiment dates back to de Grauwe et al. (1993) and has received, among others, empirical support in Kilian and Taylor (2003), Franke and Westerhoff (2012) and Kouwenberg and Zwinkels (2014) while applications include, for instance, He and Westerhoff (2005), Gaunersdorfer et al. (2007), Bauer et al. (2009) and Dieci and Westerhoff (2010). The market impact of the extrapolative rule can be formulated as

$$
w_{t}=\frac{1}{1+v\left(P_{t-1}-P^{*}\right)^{2}} \text {. }
$$

Parameter $v>0$ represents investors' sensitivity to the observed mispricing. With the bellshaped weighting function (27), the market impact of extrapolative expectations is very high (close to 1) when house prices are near to their fundamental value. In this situation, the vast majority of investors interpret any price movement away from the fundamental price as the start of a sequence of changes in the same direction, and seek to profit from it. But as the price runs away from its fundamental benchmark, an increasing proportion of investors believe that the housing market bubble may eventually burst and thus switch to the regressive predictor. The larger $v$, the faster investors turn to regressive expectations for any given mispricing.

The aggregate market expectation $P_{t, t+1}^{e}$ is modeled as a weighted average of regressive and extrapolative expectations

$$
\begin{aligned}
P_{t, t+1}^{e}=\varphi\left(P_{t-1}\right) & =w_{t}\left[P_{t-1}+\gamma\left(P_{t-1}-P^{*}\right)\right]+\left(1-w_{t}\right)\left[P_{t-1}+\theta\left(P^{*}-P_{t-1}\right)\right] \\
& =P_{t-1}+\theta\left(P^{*}-P_{t-1}\right)+(\gamma+\theta) w_{t}\left(P_{t-1}-P^{*}\right)
\end{aligned} .
$$

Interestingly, equation (28) can be rewritten in a fashion formally similar to (26), that is

$$
P_{t, t+1}^{e}-P^{*}=\left(1+\mu_{t}\right)\left(P_{t-1}-P^{*}\right), \quad \mu_{t}=\frac{\gamma-\theta v\left(P_{t-1}-P^{*}\right)^{2}}{1+\nu\left(P_{t-1}-P^{*}\right)^{2}} .
$$

The investors' average expected growth rate of the bubble, $\mu_{t}$, ranges over the interval 
$(-\theta, \gamma]$, with $\mu_{t}=\gamma>0$ for $P_{t-1}=P^{*}$ and $\mu_{t} \rightarrow-\theta<0$ for $\left|P_{t-1}-P^{*}\right| \rightarrow \infty$, and thus switches between positive and negative values depending on market circumstances. Accordingly, investors initially expect a bubble to grow, but their growth expectations slow down with the mispricing and ultimately turn negative. Note that $\varphi^{\prime}\left(P^{*}\right)=1+\gamma$, where $\gamma>0$ now denotes a constant parameter, representing the strength of the extrapolative component.

We are now in a position to refine our local stability analysis of the FSS. In Appendix C we show that our housing market model (18)-(19) with expectation scheme (27)-(28) possesses two additional steady states in the region of the parameter space defined by $\gamma>r+\delta+A / \delta:=\gamma_{P}(A)$. By combining this condition with the general discussion on stability conducted out in Section 2.4, we can conclude that the system undergoes a pitchfork bifurcation when (only) the first condition in (24) gets violated, that is, for $0<A<\hat{A}$ and increasing values of parameter $\gamma$. The stability loss of the FSS corresponds to the birth of two additional (locally stable) steady states. Furthermore, the additional non-fundamental steady states are characterized by higher (respectively lower) stationary levels of house prices and housing stock than the FSS, and therefore by a higher (respectively lower) price-rent ratio than that defined by (12). This result holds for general monotonic specifications of $I\left(P_{t}\right)$ and $R\left(H_{t}\right)$. In contrast, the (supercritical) NS bifurcation still occurs when the stability boundary is crossed for increasing values of $\gamma$ with $\hat{A}<A<1$.

The pitchfork and NS bifurcations mentioned above represent local phenomena (occurring in the vicinity of the corresponding bifurcation curves in the parameter space). As a matter of fact, numerical investigations in Section 4 confirm that for any $A$ and for sufficiently large $\gamma$, stable closed orbits no longer exist and the bi-stability structure, generated by the pitchfork bifurcation, prevails ('pitchfork scenario'). Moreover, for intermediate values of $\gamma$, two locally stable steady states may coexist with a stable closed 
orbit, which is a typical phenomenon in nonlinear dynamical models with a 'cubic' equation (Agliari et al. 2007, Dieci and Gallegati 2011).

We have illustrated the qualitative features of our switching mechanism based on equation (27) with a fixed sensitivity parameter $v$. In the following, we replace this parameter by a non-negative function $v_{t}=v\left(x_{t-1}\right)$ of price deviation $x_{t-1}:=P_{t-1}-P^{*}$, such that the weighting function (27) takes the more general form

$$
w_{t}=w\left(x_{t-1}\right)=\frac{1}{1+v\left(x_{t-1}\right) x_{t-1}^{2}}
$$

though remaining a differentiable bell-shaped curve with the following qualitative properties: $w(x)>0, \forall x, w^{\prime}(0)=0, x w^{\prime}(x)<0$ for $x \neq 0$, and $x w(x) \rightarrow 0$ as $x \rightarrow \pm \infty$. In particular, the

latter condition ensures that the market share $w_{t}$ of extrapolators vanishes as $\left(P_{t-1}-P^{*}\right) \rightarrow \pm \infty$ and that their impact on the market expectation, i.e. $\gamma\left(P_{t-1}-P^{*}\right) w_{t}$, becomes negligible. In the rest of our paper, for $v_{t}=v\left(x_{t-1}\right)$ we use the specification

$v_{t}=\left\{\begin{array}{ll}v_{L}-c_{L}\left(P_{t-1}-P^{*}\right), & P_{t-1}<P^{*} \\ v_{U}+c_{U}\left(P_{t-1}-P^{*}\right), & P_{t-1} \geq P^{*}\end{array}\right.$,

with $v_{L} \geq v_{U} \geq 0$ and $c_{L} \geq c_{U} \geq 0$, which captures the idea that the market switches more quickly and strongly to regressive beliefs in the presence of larger deviations and when the price is below its fundamental value. Note that such a specification of $v_{t}$, even discontinuous at the FSS, does not affect the differentiability of $w_{t}$, nor does it alter our local stability results.

\section{The model at work}

Guided by our analytical results, we continue with a simulation analysis to explore in more detail the dynamic interplay between speculative forces and the real side of housing markets. More precisely, this will be the subject of Section 4.2. Before doing this, we discuss in 
Section 4.1 a number of issues related to the numerical investigation of the model.

\subsection{Model calibration and parameter selection}

In Section 4.1.1, we introduce isoelastic demand and supply functions, and compute the model's FSS. In Section 4.1.2, we establish a relation between the slopes of the demand and the supply functions at the FSS and their elasticities. In Section 4.1.3, we identify relevant ranges and time dimensions for the model parameters.

\subsubsection{Demand and supply curves}

Following the housing market literature, we proceed with isoelastic demand and supply curves. Demand for housing services is specified as $D\left(R_{t}\right)=k_{0} R_{t}^{-k}$, with $k_{0}>0, k>0$, where parameter $k$ represents the constant elasticity of the demand for housing services. As a result, market clearing condition (1) yields $R\left(H_{t}\right)=m_{0} H_{t}^{-m}$, with $m:=1 / k>0$, $m_{0}:=\left(b / k_{0}\right)^{-1 / k}>0$, implying that $\tilde{R}\left(H_{t}\right)=m_{0} H_{t}^{-m}-\lambda \sigma^{2} H_{t}$. Obviously, parameter $m$ stands for the reciprocal value of the demand elasticity. The investment function is specified as $I\left(P_{t}\right)=q_{0} P_{t}^{q}$, with $q_{0}>0, q>0$, where parameter $q$ denotes the constant elasticity of the supply of new housing. Condition (9), defining the fundamental price, then turns into

$$
(r+\delta) P^{*}+\lambda \sigma^{2} \frac{q_{0}}{\delta}\left(P^{*}\right)^{q}-m_{0}\left(\frac{\delta}{q_{0}}\right)^{m}\left(P^{*}\right)^{-m q}=0,
$$

whereas the steady-state housing stock in equation (10) can be expressed as

$$
H^{*}=\frac{q_{0}}{\delta}\left(P^{*}\right)^{q}
$$

As can be shown, the solution to equation (32) is unique, although the steady-state coordinates can only be derived explicitly in the case of risk-neutral investors. For $\lambda=0$, we 
obtain $P^{*}=\left(\frac{m_{0}}{r+\delta}\right)^{\frac{1}{1+m q}}\left(\frac{\delta}{q_{0}}\right)^{\frac{m}{1+m q}}$ and $H^{*}=\left(\frac{m_{0}}{r+\delta}\right)^{\frac{q}{1+m q}}\left(\frac{q_{0}}{\delta}\right)^{\frac{1}{1+m q}}$, respectively.

We also run a number of simulations based on linear demand and supply functions. Our results suggest that the global dynamic scenarios emerging from the model's local bifurcations are quite robust with respect to changes of the demand and supply functions, and depend essentially on the interplay between their slopes at the steady state and investors' expectation formation. Details on the linear specifications are provided in Appendix D.

\subsubsection{Slopes versus elasticities}

In recent years, the impact of the supply elasticity on the dynamics of speculative housing markets has received increasing attention from the theoretical and empirical literature (Wheaton 1999, Malpezzi and Wachter 2005, Glaeser et al. 2005, 2008, Gyourko 2009). However, the general stability conditions developed in Section 2.4 are naturally expressed in terms of the slopes of the risk-adjusted inverse demand and supply curves at the FSS, and it is not possible to reformulate such general conditions directly in terms of demand and supply elasticities at the FSS, unless additional assumptions are made. ${ }^{14}$ Since empirical research usually focuses on elasticities, especially when dealing with cross-section analyses of housing markets with different demand and supply conditions (Kim et al. 2012, Paciorek 2013), we transform our model such that it allows a direct interpretation of our simulation results and a qualitative comparison with the dynamics of real housing markets and empirical findings.

We solve this issue by reformulating the risk-adjusted inverse demand and supply schedules, $\tilde{R}\left(H_{t}\right)$ and $I\left(P_{t}\right)$, such that the coordinates of the FSS are invariant with respect

\footnotetext{
14 To see the problem, denote by $\varepsilon_{I}\left(P^{*}\right):=I^{\prime}\left(P^{*}\right) P^{*} / I\left(P^{*}\right)$ the price elasticity of the housing supply at fundamental price $P^{*}$ and consider a ceteris paribus change in a parameter of supply curve $I(P)$. Since quantities $P^{*}, I\left(P^{*}\right)$, and $I^{\prime}\left(P^{*}\right):=\beta$ are all simultaneously affected by such a change, it is, in general, impossible to establish a one-to-one correspondence between slope $I^{\prime}\left(P^{*}\right)$ and elasticity $\mathcal{E}_{I}\left(P^{*}\right)$.
} 
to changes in the model parameters. As it turns out, slopes $\alpha:=-\tilde{R}^{\prime}\left(H^{*}\right)$ and $\beta:=I^{\prime}\left(P^{*}\right)$ are then directly related to elasticity parameters $m$ and $q$, respectively. Moreover, an invariant FSS facilitates the comparison of simulation runs across different parameter settings and, of course, the implicit definition (32) of the fundamental price poses no further hurdles.

Taking $P^{*}$ and $H^{*}$ as exogenous and solving (32)-(33) for the intercept parameters yields $m_{0}=\left[(r+\delta) P^{*}+\lambda \sigma^{2} H^{*}\right]\left(H^{*}\right)^{m}$ and $q_{0}=\delta H^{*}\left(P^{*}\right)^{-q}$. The endogenization of the intercept parameters allows us to rewrite $R\left(H_{t}\right)$ and $I\left(P_{t}\right)$ as the product of a steady-state component and a disequilibrium factor, i.e.

$R\left(H_{t}\right)=\left[(r+\delta) P^{*}+\lambda \sigma^{2} H^{*}\right]\left(\frac{H^{*}}{H_{t}}\right)^{m}, \quad I\left(P_{t}\right)=\delta H^{*}\left(\frac{P_{t}}{P^{*}}\right)^{q}$

implying that $\tilde{R}\left(H_{t}\right)=\left[(r+\delta) P^{*}+\lambda \sigma^{2} H^{*}\right]\left(\frac{H^{*}}{H_{t}}\right)^{m}-\lambda \sigma^{2} H_{t}$. Since we now have that $\alpha=-\widetilde{R}^{\prime}\left(H^{*}\right)=\lambda \sigma^{2}+\left[(r+\delta) \frac{P^{*}}{H^{*}}+\lambda \sigma^{2}\right] m \quad$ and $\quad \beta=I^{\prime}\left(P^{*}\right)=\delta \frac{H^{*}}{P^{*}} q$, a change in elasticities $m$ or $q$ implies a proportional change in slopes $-R^{\prime}\left(H^{*}\right)=\alpha-\lambda \sigma^{2}$ or $I^{\prime}\left(P^{*}\right)=\beta$, respectively. Hence, we can easily connect the analytical results of Sections 2 and 3 with the numerical results of Section 4 , based on parameter ranges reported by the empirical literature.

Combining (34) with (18)-(19), we obtain the two-dimensional nonlinear map

$$
\begin{aligned}
& P_{t}=\frac{\varphi\left(P_{t-1}\right)+\left((r+\delta) P^{*}+\lambda \sigma^{2} H^{*}\right)\left(H^{*}\right)^{m} H_{t}^{-m}-\lambda \sigma^{2} H_{t}}{1+r+\delta}, \\
& H_{t}=(1-\delta) H_{t-1}+\delta H^{*}\left(\frac{P_{t-1}}{P^{*}}\right)^{q},
\end{aligned}
$$

where $\varphi\left(P_{t-1}\right)$ is given by (27)-(28), and parameter $v$ may vary according to (31). 


\subsubsection{Parameter calibration}

Table 1 summarizes the base parameter set of our simulations. All parameters with a time dimension (interest and depreciation rates, parameters characterizing investors' beliefs about price movements, and volatility parameters) are first specified on an annual basis and then converted to a quarterly or monthly basis. Note that quarterly and monthly time scales are common for housing market data. For instance, the Federal Housing Finance Agency and Standard \& Poor's publish US house price data on a quarterly and monthly basis. We use the superscript $(a)$ to denote parameters specified on an annual basis, whereas $K$ denotes the frequency and $1 / K$ the length of the time step used in the simulation. For instance, $K=4$ indicates parameters rescaled to a quarterly basis. Rescaling parameters to different time units confirms the robustness of the qualitative findings of our simulation.

*** Table 1 ABOUT HERE ***

The extrapolation (regression) parameter $\gamma^{(a)}\left(\theta^{(a)}\right)$ indicates that house prices are expected to change by $\gamma^{(a)}\left(P_{t-1}-P^{*}\right)$ (by $\left.\theta^{(a)}\left(P^{*}-P_{t-1}\right)\right)$ over the next year. This roughly implies an absolute price change of $\gamma^{(a)}\left(P_{t-1}-P^{*}\right) / K$ (of $\theta^{(a)}\left(P^{*}-P_{t-1}\right) / K$ ) over the next $1 / K$ years in investors' beliefs. Although modeling (expected) absolute price changes is convenient analytically, it is also important to highlight the impact of parameters $\gamma^{(a)}$ and $\theta^{(a)}$ on relative price changes. Denoting by $\tau:=\left(P_{t-1}-P^{*}\right) / P^{*}$ the current relative deviation of the price from its fundamental value, the (expected) relative price changes under extrapolative and regressive beliefs are given by $\frac{P_{t, t+1, E}^{e}-P_{t-1}}{P_{t-1}}=\frac{\gamma^{(a)} \tau}{K(\tau+1)} \quad$ and $\frac{P_{t, t+1, R}^{e}-P_{t-1}}{P_{t-1}}=-\frac{\theta^{(a)} \tau}{K(\tau+1)}$. For instance, with the parameters specified in Table 1 and the housing market overvalued by as much as $20 \%$, fundamentalists would expect a relative downward price correction of $2.083 \%$ over the next quarter, whereas extrapolators would 
expect a relative upward movement of $2.5 \%$ over the same time horizon.

For simplicity, we set the parameter expressing investors' second-moment beliefs (annual price volatility) equal to a fixed proportion of the fundamental price, $\sigma^{(a)}=\chi^{(a)} P^{*}$, where $\chi^{(a)}=4 \%$, and $\sigma=\sigma^{(a)} / \sqrt{K}=\chi^{(a)} P^{*} / \sqrt{K}$ is the parameter rescaled to the time unit. Based on equation (12), the risk-aversion coefficient is defined residually from the (exogenously assumed) risk premium, namely, $\lambda=\frac{\xi}{\sigma^{2}} \frac{P^{*}}{H^{*}}=\frac{\xi^{(a)}}{\sigma^{(a)^{2}}} \frac{P^{*}}{H^{*}}=0.00125$. In some simulations i.i.d. (normal) noise is added to house prices, ${ }^{15}$ with zero mean and annual standard deviation $\sigma_{P}^{(a)}$. In Figures 9 and 10, for instance, we select $\sigma_{P}^{(a)}=\sigma^{(a)}=\chi^{(a)} P^{*}=4 \% P^{*}$, consistent with investors' conditional volatility parameter. With our base parameter set, the asymmetric switching function (30) implies that investors turn to regressive expectations more quickly in undervalued markets than in overvalued markets. ${ }^{16}$

A few further comment should be given concerning supply and demand elasticity parameters $q$ and $k=1 / m$ and depreciation rate $\delta$. We vary supply elasticity $q$, which represents the main focus of our simulation analysis, within the range [1,5] . While earlier empirical literature reports supply elasticities between 1 and 4, larger elasticities have been observed more recently (Malpezzi and Maclennan 2001, Green et al. 2005 and references therein). Empirical evidence about the demand elasticity is scant and, partly due to the variety of existing house price measures, varies considerably across housing markets (Hanushek and Quigley 1980, Mayo 1981, Hendershott et al. 2002, Riddel 2004). Overall, demand elasticities seem to be well below one, and thus $k \in(0.2,0.8)$ seems to be a reasonable simulation range.

\footnotetext{
${ }^{15}$ Note that the noise added to the simulation is dynamical noise, directly affecting the state and the future evolution of the system, instead of simple observational noise imposed after the price path has been simulated.

${ }^{16}$ In our numerical investigation, we select an asymmetric specification of the switching function just because it can produce negative bubbles that are less pronounced than positive bubbles, as suggested by empirical evidence. However, this particular specification is not key to the dynamic features of our model discussed in Sections 4.2 and 4.3, as confirmed by a robustness check using its symmetric counterpart with a fixed sensitivity parameter.
} 
In our base parameter set, we assume, for instance, $k=0.25$, implying that $m=4$. The literature on housing depreciation is richer, revealing values between $1 \%$ and $3 \%$ per year (Harding et al. 2007). However, what really matters for the dynamics of our model is the user cost $(r+\delta+\xi)$ at the FSS, which in our setting corresponds to $6 \%$ per year. The reciprocal of this value represents the steady-state value of the annualized price-rent ratio, and is given as $\pi^{*(a)}:=\frac{1}{K} \frac{P^{*}}{R\left(H^{*}\right)}=\frac{1}{r^{(a)}+\delta^{(a)}+\xi^{(a)}} \approx 16.67$, close to average price-rent ratios reported by the empirical literature (Himmelberg et al. 2005, Campbell et al. 2009).

Our base parameter set implies that $\alpha=0.065, \beta=0.005 q$, and $\alpha \beta=3.25 q 10^{-4}$. In all of our experiments, the real parameters (slopes/elasticities, interest rate, and depreciation) thus satisfy restriction (17), and therefore condition (16). If expectations were homogeneous and rational, the system would be saddle-path stable and would always converge monotonically to the FSS. On the one hand, this means that all disequilibrium phenomena we illustrate below are driven by expectations. On the other hand, the strong sensitivity of the model's dynamics to parameter changes within region (17) highlights the fact that the conditions of the real economy can heavily shape expectations-driven housing market dynamics.

\subsection{The joint impact of real and speculative forces}

This section studies the basic mechanisms of the joint impact of real and speculative forces on the dynamics of housing markets. In Section 4.2.1, we show the extent to which our BRHA model is able to mimic the dynamics of the perfect-foresight model. In Sections 4.2.2 and 4.2.3, we explore how real and speculative forces affect the amplitude and duration of housing market bubbles, respectively. 


\subsubsection{Mimicking the perfect-foresight case}

Let us start with an example in which the housing market dynamics behaves qualitatively similarly to the perfect-foresight case. By assuming a weak extrapolation, strong beliefs in mean reversion and a low supply elasticity, Figure 3 (left panel) shows the adjustment trajectories of house prices and housing stock towards their FSS levels, when both variables are initially $4 \%$ below their long-run equilibrium levels. ${ }^{17}$ The adjustment path is indeed very similar to that sketched in Figure 1, with a unique price overshooting episode and no overbuilding. Although investors are heterogeneous and not fully rational, the BRHA model dynamics may nevertheless mimic the perfect-foresight dynamics. However, the parameter constellations that produce this kind of qualitative dynamics are restricted to a very narrow region of the parameter space where, in particular, the supply elasticity is well below the range reported in empirical studies. The right panel in Figure 3 shows the effect of a larger supply elasticity along with a larger extrapolation rate. The combined effect of these two parameters can take the dynamics very far away from the adjustment pattern observed under perfect foresight.

\section{*** FIGURE 3 ABOUT HERE ***}

\subsubsection{Amplitude of housing bubbles and price swings}

We continue our analysis by using bifurcation diagrams to relate the magnitude of steadystate mispricing and the amplitude of price swings to extrapolation parameter $\gamma$ and elasticities $k$ and $q$ (or, equivalently, demand and supply slopes). The effect of an increase in parameter $\gamma$ is in perfect accordance with the properties of related BRHA financial market models (Day and Huang 1990, Brock and Hommes 1998). This is shown in the top panels in Figure 4. The stronger the investors' extrapolation, the larger the steady-state deviations of $P$

\footnotetext{
${ }^{17}$ In all the plots of this section, $P$ and $H$ are represented in relative deviations from the FSS.
} 
and $H$ from $P^{*}$ and $H^{*}$ in the pitchfork scenario (right area of the plots), or the amplitude of the price swings in the NS scenario (left area of the plots). ${ }^{18}$

*** FIGURE 4 ABOUT HERE ***

The impact of the supply and demand elasticity ( $q$ and $k=1 / m$, respectively) on mispricing and price swings is shown in the middle and bottom panels in Figure 4, respectively. In the pitchfork scenario, the steady-state price deviation from the fundamental price decreases with $q$ and increases with $k$, while the deviation of the steady-state stock increases with both $q$ and $k$. Thus, a prompter response of the housing supply results in smaller bubbles and larger stock adjustments, whereas a more elastic demand for housing services implies larger bubbles and larger stock adjustments. In the NS scenario (rightmost portion of the middle panels and leftmost portion of the bottom panels), the amplitude of price fluctuations does not change significantly with $q$ or $k$, whereas the amplitude of stock fluctuations increases moderately with $q$ and substantially with $k$, consistent with the corresponding pitchfork scenario. Overall, the reported effects of supply and demand elasticity are in agreement with our intuition. In particular, supply and demand elasticity have a similar effect on housing stock, as is clear from a comparison of the middle and bottom right panels. $^{19}$

\subsubsection{Duration and robustness of housing bubbles: the impact of the supply elasticity}

How does the supply elasticity affect the duration of housing market bubbles and their sensitivity to exogenous shocks? Figure 5 shows examples of deterministic housing market

\footnotetext{
18 The sudden switching behavior in Figure 4 is due to coexisting attractors: as parameters change, the boundaries of the basins of attraction shift, and initial values may be located in different basins of attraction.

${ }^{19}$ In other words, the stock increase due to a large price elasticity of supply is weaker - ceteris paribus - in the presence of inelastic demand for housing services: if demand is inelastic, a stock increase also triggers a larger downward adjustment of the rent, which, in turn, tends to dampen the growth of the price and of the housing stock.
} 
bubbles for different supply elasticities. In each simulation, the initial price is set $1 \%$ larger than the fundamental price. The parameter setting is chosen in the NS scenario except for the top-left panel, which corresponds to the pitchfork scenario. It is clear from the plots that the rate of stock accumulation, determined by the elasticity of the supply of new constructions, is crucial as to how long prices will continue to rise. The top-left panel (with a low elasticity), suggests that if elasticity remains below a certain level, house prices initially rise and then fall asymptotically towards a non-fundamental steady state with a permanent positive bubble component. For a larger elasticity, however, the housing stock grows quickly enough to first slow down the price growth and then reverse it, as shown in the other three panels. ${ }^{20}$ Apparently, a larger supply elasticity $q$ also results in shorter cycles and a stronger housing stock response. Similar experiments (not reported) show that a larger demand elasticity in the rental market (that is, a smaller $m$ ) tends to increase the length of the cycles.

\section{*** FIGURE 5 ABOUT HERE ***}

When two locally attracting non-fundamental steady states (or bubble equilibria) coexist, we may regard their distances from their basin boundaries as indicators of their robustness, somehow related to the likely duration of a bubble. From this perspective, the supply and demand elasticities play a similar role here as in the NS scenario. In fact, the deterministic bubble equilibria become more and more fragile (in terms of their basins of attraction) as parameters $q$ and $m$ increase. Figure 6 shows the basins of attraction (light gray area) of the upper non-fundamental steady state (NFSS) for increasing values of the supply elasticity, demonstrating that the NFSS gets closer and closer to the boundary of its basin of attraction. For instance, in the top-left panel of Figure 6, corresponding to the scenario in the top-left panel of Figure 5, the upper NFSS is more distant to the boundary of

\footnotetext{
${ }^{20}$ Although the cycle length in Figure 5 is unrealistic, it becomes much more realistic once exogenous noise is added to the model. In Figures 9 and 10, for instance, the cycle length is given as 40 to 60 periods, corresponding to 10 to 15 years.
} 
its basin of attraction than in the bottom-left panel of Figure 6. As a result, the exemplary deterministic trajectory (black dots) in the bottom-left panel, starting near the FSS, comes relatively close to the basin boundary as it approaches the NFSS.

*** FIGURE 6 ABOUT HERE ***

As suggested by the time plots in Figure 7, this phenomenon makes a bubble less robust to exogenous price shocks. Figure 7 represents the model dynamics when a zero-mean i.i.d. normal price shock is added to the deterministic scenarios depicted in Figure 6. In the top-left panel, house prices and the housing stock remain within the basin of attraction of the upper NFSS, despite the exogenous shocks, and thus fluctuate around the bubble equilibria. In the top-right and bottom-left panels of Figure 7, however, the trajectories are eventually pushed out of the basins of attraction of the NFSS, and thus house prices and the housing stock fall rapidly and move towards the lower NFSS.

*** FIGURE 7 ABOUT HERE ***

The bottom-right panel in Figure 6 shows that the basin of attraction of the upper NFSS may even become very small. In such a situation (foreshadowing a subcritical NS bifurcation of the bubble equilibrium), the basin boundary of the steady state is an unstable curve that separates it from the basin of a coexisting stable curve. This transition from bistability (the pitchfork scenario, where the phase space is shared between two locally stable steady states) to the mixed scenario depicted here (coexistence of one or more locally stable equilibria and other attractors) is often associated with complex and highly unpredictable dynamic patterns (Agliari et al. 2005). For instance, the exemplary deterministic trajectory starting near the FSS (white dots) approaches the NFSS quite closely, but does not enter its basin of attraction. The corresponding stochastic time plot in the bottom-right panel of Figure 7 shows an immediate and rapid decline of house prices, followed by a reduction in the housing stock. These simulations suggest that even small changes in the supply elasticity (or in other real or behavioral parameters) can have a marked effect on housing market dynamics. 
Our qualitative results in this section, as well as those in the previous section, are in agreement with recent research into the impact of supply conditions on the nature of housing market bubbles, showing that a more elastic housing supply is likely to result in shorter bubbles, smaller price increases and stronger stock adjustments (Glaeser et al. 2008, Grimes and Aitken 2010). Furthermore, our numerical results are robust with respect to the choice of alternative functional forms of demand and supply curves and of different time units, provided that the parameters are properly rescaled (see Section 4.1.3 and Appendix D for details). As an example, Figure 8 reports the results of a simulation under the linear case with a quarterly (top panel) and monthly time scale (middle and bottom panels), with parameters as in Figure 5. The elasticities of demand and supply curves at the FSS are equal to $q=1$ (left panels, pitchfork scenario) or $q=4$ (right panels, NS scenario). As can be seen, such different specifications do not appear to change the local and/or global (qualitative) outcomes illustrated above. The model behavior thus depends essentially on our qualitative assumptions about the housing supply and demand and investors' expectation formation.

*** FIGURE 8 ABOUT HERE ***

\subsection{Price-to-rent ratios, overbuilding, expectations, and market crashes}

Figures 9 and 10 show stochastic simulations of our model. The joint examination of the dynamics of house prices and the housing stock (top panels), market impact of regressive expectations (middle panels) and price-rent ratios (bottom panels) sheds light on the mechanisms behind the bubble and crash behavior of housing markets and the complex interplay between real and speculative forces. Demand for housing services and new constructions are specified as isoelastic functions. The parameters are set as in Figure 5, bottom-left panel, with the annual standard deviation of the i.i.d. noise equal to $4 \%$ of the fundamental price. 
Our main observations may be summarized as follows. First, the time path of the housing stock is much smoother than the noisy price path, as expected, given that the resulting noise on the amount of new constructions is of little importance compared with the existing stock. More importantly, there is a mismatch between the fluctuations and turning points of house prices and housing stocks. Since in our model new housing investment depends on current prices, the stock may even increase in periods in which the price is already declining, provided that new investment more than offsets depreciation. This result is in agreement with the literature (Grenadier 1996, DeCoster and Strange 2012), pointing out that developers' behavior may lead to overbuilding, even in the face of a declining demand and a reduction in house prices.

Second, since the rent is inversely related to the stock, the price-rent ratio increases and may reach very high levels during market phases in which both price and stock increase. When prices decline but the stock continues to grow, the price-rent ratio may start to decrease, remain constant or even increase further. In general, the price-rent ratio declines sharply after the turning points of the housing stock, because in such periods the price decline occurs simultaneously with a rise in the rent, which is inversely related to the stock of housing. ${ }^{21}$ Overall, house prices start to decline more sharply once the price-rent ratio has reached its maximum. This is in agreement with the signaling power conventionally ascribed to the pricerent ratio, in that the maximum of the price-rent ratio tends to coincide with the start of the more dramatic phase of a crash. Overall, the steady-state value of the price-rent ratio with 16.67 is not far from reported long-term average values. Moreover, the price-rent ratios in Figures 9 and 10 achieve quite realistic levels during bubble phases (Campbell et al. 2009).

\footnotetext{
${ }^{21}$ Note that our model abstracts from possible exogenous growth factors affecting housing demand and the rent level. Introducing exogenous growth in the ceteris paribus relationship between the rent level and the housing stock (e.g., along the lines of Wheaton 1999), would allow the two variables to move in the same direction, yet preserving the dynamic behavior of the price-rent ratio illustrated here.
} 
Third, and presumably most importantly, let us roughly define a crash as a phase in which the price declines sharply from very high values to pre-bubble levels, close to (or even below) the fundamental price, without remarkable intermediate phases of recovery. Visual inspection reveals that a sustained price decline does not always result in a crash. In fact, the occurrence and timing of a crash in our model depend on a combination of market expectations and the dynamics of the housing stock. ${ }^{22}$ When both the price level and market impact of regressive expectations are sufficiently high, the price starts to decline. However, this only results in a crash if the housing stock is also very high (which is mirrored by a very high price-rent ratio). Significant examples can be found in Figure 9 (periods $t_{A}=62$ and $\left.t_{B}=71\right)$ and Figure 10 (periods $t_{C}=140$ and $\left.t_{D}=148\right)$.

In Figure 9, a big crash of more than $15 \%$ starts in period $t_{B}=71$, when the impact of regressive expectations is around $76 \%$ or, put differently, when the proportion of investors who believe that the bubble will persist is $24 \%$. Price level and market sentiment in period $t_{B}$ are very similar to the situation in period $t_{A}=62$, when the price also starts to decline sharply. In this case, however, an initial $6 \%$ price dip is followed by a remarkable recovery over 4 quarters prior to period $t_{B}$. In Figure 10, the impact of regressive expectations in period $t_{C}=140$ (about 69\%) is much larger than in period $t_{D}=148$ (about 56\%), yet the price decline that starts in period $t_{C}$ is followed by a tentative recovery over the next 5 quarters, whereas the crash occurring in period $t_{D}$ is much bigger (about $-16 \%$ over 5 quarters). The remarkable difference between periods $t_{C}$ and $t_{D}$, as well as between periods $t_{A}$ and $t_{B}$ in Figure 9, is that the stock of housing has substantially increased from the initial to the final period of each interval. Since new investments are a non-negative quantity and depreciation is a small fraction of the housing stock, stock adjustments are bounded from below. Due to the

\footnotetext{
${ }^{22}$ Shiller (2007) discusses such a scenario concerning Greater London's home prices in 2004-2005.
} 
downward rigidity of the housing supply, the combination of a high stock and a falling demand can amplify any price reduction.

A final comment needs to be made. The existence of two possible bifurcation routes and the variety of dynamic scenarios generated by the model are ultimately due to the doubleedged effect of expectations in our model. ${ }^{23}$ There is a positive feedback effect (demanddriven and typical of speculative asset markets), by which higher (lower) expected prices tend to drive prices further up (down). However, a negative feedback effect (supply-driven and typical of cobweb markets with a production lag) is also at work in our model. High prices stimulate housing investments by developers with naïve expectations, which tend to increase the housing stock. ${ }^{24}$ In addition, a larger housing stock reduces the rent level (i.e. the dividend component of the return) and tends to lower the demand for housing stock. A high supply of housing stock and a low demand for housing stock naturally counter the pressure on prices generated by the positive feedback effect. While the destabilizing positive feedback effect dominates the housing market dynamics near the FSS and can trigger housing market bubbles, the negative feedback effect eventually becomes stronger and leads to more orderly markets.

\section{Conclusions and further research}

The literature on real estate and urban economics argues that extrapolative beliefs and other behavioral factors play a substantial role in the development and bursting of housing market bubbles. Recent literature also indicates that such disequilibrium phenomena, triggered by boundedly rational and heterogeneous investors, may interact in complex ways with the real side of housing markets and, as a consequence, remarkable differences can be observed

\footnotetext{
${ }^{23}$ We thank Cars Hommes for pointing this out to us.

${ }^{24}$ If supply and rent are kept fixed in this model, i.e. $H_{t}=H^{*}$ and $R\left(H_{t}\right)=R\left(H^{*}\right)$, then just two scenarios are possible, namely, stability of the FSS or the pitchfork scenario, depending on whether regressive or extrapolative expectations prevail.
} 
among markets with different structural and institutional characteristics, in particular with respect to the markets' supply elasticity.

Our stylized and tractable BRHA stock-flow housing market model can provide clearcut qualitative insights into the relationship between real and speculative forces, most of which are in agreement with empirical findings. In particular, the model shows that (i) an inelastic supply results in longer and more persistent bubbles, (ii) the level of overbuilding reached during the boom phase is, along with changes in market expectations, a crucial factor for the timing and size of subsequent crashes, and (iii) the price-rent ratio may be used as a warning indicator to predict the collapse of housing market bubbles.

Future research should focus, first of all, on the policy implications of our model, concerning, for instance, rental regulations, land use and supply constraints, housing taxation and, most importantly, interest rates. As a first step, this could be performed by conducting an extensive investigation of the impact of the parameters which would be affected by such policies, in particular, the user cost and supply and demand elasticities. The dynamic analysis undertaken in this paper strongly suggests that the impact of any policy will depend heavily on the behavioral parameters that characterize investors' reactions. Models similar to ours can thus be used as laboratories to conduct policy experiments to assess the qualitative and quantitative impact of various kinds of interventions, thereby managing complex economic dynamics.

Furthermore, since our setup is very simple and mainly oriented at investigating the joint (qualitative) impact of extrapolative behavior and a few crucial parameters of the economy, several important aspects of housing markets have been omitted. These include development lags and developers' strategic behavior, the effect of vacancy rates on rental adjustments and, most importantly, credit conditions and the impact of interest rate changes. The latter issue is crucial for policy makers as well as highly debated in the academic literature (see, e.g. Himmelberg et al. 2005, Jordà et al. 2015), and would deserve a dedicated 
study. Indeed, our model framework can provide a number of insights into the impact of interest rate policies. While it is immediately clear from the theoretical analysis in Section 2.4 that increasing the interest rate $r$ stabilizes the economy (by widening the local stability region of the FSS in the parameter space), it would be interesting to investigate numerically whether and how interest rate policies can help to avoid 'noise-induced' housing crashes in the presence of multiple locally stable equilibria, as in the situations depicted in Section 4.2.3. Moreover, preliminary numerical results (not reported here) suggest that the central bank can reduce price volatility by dynamically adjusting the interest rate according to observed market mispricing.

A somehow related issue concerns the impact of good credit conditions on investors' beliefs and price dynamics during the bubble phase. Although mean reverting forces ultimately prevail in our stylized nonlinear framework, simple analytical arguments and numerical experiments suggest that (expectations of) interest rate reductions and better credit conditions can strengthen and prolong the impact of optimistic extrapolators even in the presence of very high and increasing prices, in agreement with the empirical findings of Piazzesi and Schneider (2009) for the U.S. housing boom. For instance, if central banks decrease the interest rate during a housing market boom, speculators adjust their perception of the fundamental house price upwards. Since the housing market may then appear less overvalued, the market impact of extrapolators may remain high for an extended period of time, driving house prices to even higher levels.

Finally, in order to keep our model as simple as possible, we do not allow for possible imbalances and assume market clearing in each period on the property market. In other words, our setup neglects the widely reported phenomenon of the downward rigidity of house prices, by which falling demand tends to reduce transactions and new housing starts, rather than 
being immediately reflected in lower prices. ${ }^{25}$ All this needs to be taken into account in future work, which should also be directed towards calibrating and estimating similar BRHA housing market models.

\section{Acknowledgements}

This work was carried out with the financial support of MIUR - PRIN 2009NZNM7C "Local interactions and global dynamics in economics and finance: models and tools", and under the auspices of COST Action IS1104 "The EU in the new complex geography of economic systems: models, tools and policy evaluation". Earlier versions of this paper were presented at the Workshop "Teorie matematiche della Crisi", Milano, Italy (2014), the Workshop "Deterministic and Stochastic Dynamics in Economics and Finance", Pisa, Italy (2013), the 7th International Conference on Nonlinear Economic Dynamics" (NED11), Cartagena, Spain (2011), the Workshop "Modelli Dinamici in Economia e Finanza" (MDEF 2010), Urbino, Italy (2010), and the "Rimini Conference in Economics and Finance" (RCEF), Rimini, Italy (2010), as well as at seminars at UTS, Sydney (2012) and Università Cattolica del Sacro Cuore, Piacenza, Italy (2011). We thank the participants for their stimulating discussions.

\section{References}

Adam, K., Kuang, P. and Marcet, A. (2011): House price booms and the current account. NBER Working Paper No. 17224.

Agliari, A., Dieci, R., Bischi, G.I. and Gardini, L. (2005): Global bifurcation of closed invariant curves in two-dimensional maps: a computer-assisted study. International Journal of Bifurcation and Chaos in Applied Sciences and Engineering, 15, 1285-1328.

Agliari, A., Dieci, R. and Gardini, L. (2007): Homoclinic tangles in a Kaldor-like business

\footnotetext{
${ }^{25}$ Dieci and Westerhoff (2012) perform a preliminary investigation of the impact of such factors within a simple dynamic framework where house price changes are driven by excess demand.
} 
cycle model. Journal of Economic Behavior and Organization, 62, 324-347.

Barras, R. (2005): A building cycle model for an imperfect world. Journal of Property Research, 22, 63-96.

Bauer, C., de Grauwe, P. and Reitz, S. (2009): Exchange rate dynamics in a target zone - a heterogeneous expectations approach. Journal of Economic Dynamics and Control, 33, 329-344.

Bolt, W., Demertzis, M., Diks, C., Hommes, C. and van der Leij, M. (2014): Identifying booms and busts in house prices under heterogeneous expectations. CeNDEF Working paper 14-13, University of Amsterdam.

Boswijk, P., Hommes, C. and Manzan, S. (2007): Behavioral heterogeneity in stock prices. Journal of Economic Dynamics and Control, 31, 1938-1970.

Branch W.A. and Evans G.W. (2011): Learning about risk and return: a simple model of bubbles and crashes. American Economic Journal: Macroeconomics, 3, 159-191.

Brock, W. and Hommes, C. (1998): Heterogeneous beliefs and routes to chaos in a simple asset pricing model. Journal of Economic Dynamics Control, 22, 1235-1274.

Brunnermeier, M.K. and Julliard, C. (2008): Money illusion and housing frenzies. Review of Financial Studies, 21, 135-180.

Burnside, C., Eichenbaum, M. and Rebelo, S. (2012): Understanding booms and busts in housing markets. CQER Working Paper 12-02, Federal Reserve Bank of Atlanta.

Campbell, S.D., Davis, M.A., Gallin, J. and Martin, R.F. (2009). What moves housing markets: a variance decomposition of the rent-price ratio. Journal of Urban Economics, 66 , 90-102.

Case, K. and Shiller, R. (1989): The efficiency of the market for single-family homes. American Economic Review, 79, 125-137.

Case, K. and Shiller, R. (1990): Forecasting prices and excess returns in the housing market. Journal of the American Real Estate and Urban Economics Association, 18, 253-273.

Chiarella, C. (1992): The dynamics of speculative behavior. Annals of Operations Research, $37,101-123$. 
Chiarella, C., Dieci, R. and He, X.-Z. (2007): Heterogeneous expectations and speculative behavior in a dynamic multi-asset framework. Journal of Economic Behavior and Organization, 62, 402-427.

Chiarella, C., Dieci, R. and He, X.-Z. (2009): Heterogeneity, market mechanisms, and asset price dynamics. In: Hens, T. and Schenk-Hoppé, K.R. (eds.): Handbook of Financial Markets: Dynamics and Evolution. North-Holland, Amsterdam, 277-344.

Chiarella, C., He, X.-Z. and Hommes, C. (2006a): A dynamic analysis of moving average rules. Journal of Economic Dynamics and Control, 30, 1729-1753.

Chiarella, C., He, X.-Z. and Wang, D. (2006b): A behavioral asset pricing model with a time varying second moment. Chaos, Solitons and Fractals, 29, 535-555.

Chinloy, P. (1996). Real estate cycles and empirical evidence. Journal of Housing Research, 7 , 173-190.

Clayton, J. (1996): Rational expectations, market fundamentals and housing price volatility. Real Estate Economics, 24, 441-470.

Cutler, D.M, Poterba J.M. and Summers, L.H. (1991): Speculative dynamics. The Review of Economic Studies, 58, 529-546.

Day, R. and Huang, W. (1990): Bulls, bears and market sheep. Journal of Economic Behavior and Organization, 14, 299-329.

De Grauwe, P., Dewachter, H. and Embrechts, M. (1993): Exchange Rate Theory - Chaotic Models of Foreign Exchange Markets. Blackwell, Oxford.

DeCoster, G. P. and Strange, W. C. (2012). Developers, herding, and overbuilding. Journal of Real Estate Finance and Economics, 44, 7-35

Díaz, A. and Luengo-Prado, M.J. (2008): On the user cost and homeownership. Review of Economic Dynamics, 11, 584-613.

Dieci R. and Gallegati, M. (2011): Multiple attractors and business fluctuations in a nonlinear macro-model with equity rationing. Mathematical and Computer Modelling, 53, 1298-1309. 
Dieci, R. and Westerhoff, F. (2010): Heterogeneous speculators, endogenous fluctuations and interacting markets: a model of stock prices and exchange rates. Journal of Economic Dynamics and Control, 34, 743-764.

Dieci, R. and Westerhoff, F. (2012): A simple model of a speculative housing market. Journal of Evolutionary Economics, 22, 303-329.

Dieci, R. and Westerhoff, F. (2013): Modeling house price dynamics with heterogeneous speculators. In: Bischi, G.I., Chiarella, C. and Sushko, I. (eds): Global Dynamics in Economics and Finance. Essays in Honour of Laura Gardini. Springer, Berlin, 35-61.

DiPasquale, D. and Wheaton W.C. (1992): The markets for real estate assets and space: a conceptual framework. Journal of American Real Estate and Urban Economics Association, 20, 181-197.

Eichholtz, P., Huisman, R, and Zwinkels, R. (2015): Fundamentals or trends? A long-term perspective on house prices. Applied Economics, 47, 1050-1059.

Favilukis, J., Ludvigson, S.C. and Van Nieuwerburgh, S. (2013): The macroeconomic effects of housing wealth, housing finance, and limited risk-sharing in general equilibrium. Working Paper, New York University.

Franke, R. and Westerhoff, F. (2012): Structural stochastic volatility in asset pricing dynamics: estimation and model contest. Journal of Economic Dynamics and Control, 36, 1193-1211.

Gallin, J. (2008): The long-run relationship between house prices and rents. Real Estate Economics, 36, 635-658.

Gaunersdorfer, A. (2000): Endogenous fluctuations in a simple asset pricing model with heterogeneous beliefs. Journal of Economic Dynamics and Control, 24, 799-831.

Gaunersdorfer, A. and Hommes, C.H. (2007): A nonlinear structural model for volatility clustering. In: Teyssière, G. and Kirman, A. (eds.): Long Memory in Economics. Springer, Berlin, 265-288.

Geanakoplos, J., Axtell, R., Farmer, D., Howitt, P., Conlee, B., Goldstein, J., Hendrey, M., Palmer, N.M. and Yang, C.Y. (2012): Getting at systemic risk via an agent-based model of the housing market. American Economic Review, Papers and Proceedings, 102, 53-58. 
Glaeser, E. and Gyourko, J. (2007): Housing dynamics. HIER Discussion Paper 2137.

Glaeser, E., Gyourko, J. and Saks, R.E. (2005): Why have house prices gone up? American Economic Review, Papers and Proceedings, 95, 329-333.

Glaeser, E., Gyourko, J. and Saiz, A. (2008): Housing supply and housing bubbles. Journal of Urban Economics, 64, 198-217.

Green, R.K., Malpezzi, S. and Mayo, S.K. (2005): Metropolitan-specific estimates of the price elasticity of supply of housing, and their sources. American Economic Review Papers and Proceedings, 95, 334-339.

Grenadier, S.R. (1996): The strategic exercise of options: development cascades and overbuilding in real estate markets. Journal of Finance, 51, 1653-1679.

Grimes, A. and Aitken, A. (2010): Housing supply, land costs and price adjustment. Real Estate Economics, 38, 325-353.

Gyourko, J. (2009): Housing supply. Annual Review of Economics, 1, 295-318.

Hanushek, E.A. and Quigley, J.M. (1980): What is the price elasticity of housing demand? Review of Economics and Statistics, 62, 449-454.

Harding, J.P., Rosenthal, S.S. and Sirmans, C.F. (2007): Depreciation of housing capital, maintenance, and house price inflation: estimates from a repeat sales model. Journal of Urban Economics, 61, 193-217.

Haughwout, A., Peach, R.W., Sporn, J. and Tracy, J. (2012): The supply side of the housing boom and bust of the 2000s. Federal Reserve Bank of New York Staff Reports, no. 556.

He, X.-Z. and Westerhoff, F. (2005): Commodity markets, price limiters and speculative price dynamics. Journal of Economic Dynamics and Control, 29, 1577-1596.

Hendershott, P.H., MacGregor, B.D. and Tse R.Y.C. (2002): Estimation of the rental adjustment process. Real Estate Economics, 30,165-183.

Himmelberg, C., Mayer, C. and Sinai, T. (2005): Assessing high house prices: bubbles, fundamentals and misperceptions. Journal of Economic Perspectives, 19, 67-92.

Hommes, C. (2013). Behavioral Rationality and Heterogeneous Expectations in Complex Economic Systems. Cambridge University Press: New York. 
Hommes, C. and Wagener, F. (2009): Complex evolutionary systems in behavioral finance. In: Hens, T. and Schenk-Hoppé, K.R. (eds.): Handbook of Financial Markets: Dynamics and Evolution. North-Holland, Amsterdam, 217-276.

Iacoviello, M. (2005). House prices, borrowing constraints, and monetary policy in the business cycle. American Economic Review, 95, 739-764.

Jordà, Ò, Schularick, M. and Taylor, A.M. (2015): Betting the house. Journal of International Economics, 96, S2-S18.

Kilian, L. and Taylor, M. (2003): Why is it so difficult to beat the random walk forecast of exchange rates? Journal of International Economics, 60, 85-107.

Kim, K.-H., Phang, S.-Y. and Wachter, S. (2012): Supply elasticity of housing. In: Smith, S.J. et al. (eds.): International Encyclopaedia of Housing and Home, Vol. 7, Elsevier, Oxford, 66-74.

Kouwenberg, R. and Zwinkels, R. (2014): Forecasting the US housing market. International Journal of Forecasting, 30, 415-425.

Lee, G.S. (1999): Housing cycles and the period of production. Applied Economics, 31, 12191230.

Lewellen J. and Shanken J. (2002): Learning, asset-pricing tests, and market efficiency. Journal of Finance, 57, 1113-1145.

Lux, T. (2009): Stochastic behavioural asset-pricing models and the stylized facts. In: Hens, T. and Schenk-Hoppé, K.R. (eds.): Handbook of Financial Markets: Dynamics and Evolution. North-Holland, Amsterdam, 161-216.

Malpezzi, S. and Maclennan D. (2001): The long-run price elasticity of supply of new residential construction in the United States and the United Kingdom. Journal of Housing Economics, 10, 278-306.

Malpezzi, S. and Wachter, S. (2005): The role of speculation in real estate cycles. Journal of Real Estate Literature, 13, 143-164.

Mayo, S.K. (1981): Theory and estimation in the economics of housing demand. Journal of Urban Economics, 10, 95-116. 
McCue, D. and Belsky, E.S. (2007): Why do house prices fall? Perspectives on the historical drivers of large nominal house price declines. Working Paper W07-3. Joint Center for Housing Studies, Harvard University.

Medio, A. and Lines, M. (2001): Nonlinear Dynamics: A Primer. Cambridge University Press, Cambridge.

Paciorek, A. (2013): Supply constraints and housing market dynamics. Journal of Urban Economics, 77, 11-26.

Piazzesi, M. and Schneider, M. (2009): Momentum traders in the housing market: survey evidence and a search model. American Economic Review, Papers and Proceedings, 99, 406-411.

Poterba, J.M. (1984): Tax subsidies to owner-occupied housing: an asset market approach. Quarterly Journal of Economics, 99, 729-752.

Poterba, J.M. (1991): House price dynamics: the role of tax policy and demography. Brookings Papers on Economic Activity, 2, 143-203.

Poterba, J.M. (1992): Taxation and housing: old questions, new answers. American Economic Review, 82, 237-242.

Riddel, M. (2004): Housing-market disequilibrium: an examination of housing-market price and stock dynamics 1967-1998. Journal of Housing Economics, 13, 120-135.

Shiller, R. (2005): Irrational Exuberance, 2nd Edition. Princeton University Press, Princeton.

Shiller, R. (2007): Understanding recent trends in house prices and home ownership. Cowles Foundation Discussion Paper No. 1630. Yale University, New Haven.

Shiller, R. (2008): Historical turning points in real estate. Eastern Economic Journal, 34, 1-13.

Turnovsky, S. (2000): Methods of Macroeconomic Dynamics, 2nd Edition. MIT Press, Cambridge, MA.

Wheaton, W. (1999): Real estate "cycles": some fundamentals". Real Estate Economics, 27, 209-230.

Westerhoff, F. and Franke, R. (2011): Converse trading strategies, intrinsic noise and the stylized facts of financial markets. Quantitative Finance, 12, 425-436. 


\section{Appendix}

\section{A) Parameter region of complex eigenvalues of the Jacobian matrix}

The eigenvalues of the Jacobian matrix (20) are complex if and only if $\operatorname{Tr}^{2}-4 D e t<0$, where the trace $T r$ and determinant Det of (20) are expressed according to (23). With simple algebra, one obtains $\frac{[(1+\gamma)-\alpha \beta-(1-\delta)(1+r+\delta)]^{2}-4 \alpha \beta(1-\delta)(1+r+\delta)}{(1+r+\delta)^{2}}<0 \quad, \quad$ or, equivalently $|(1+\gamma)-(A+B)|<2 \sqrt{A B}$, where $A:=\alpha \beta, B:=(1-\delta)(1+r+\delta)$. Rearranging terms finally yields $(A+B)-2 \sqrt{A B}<(1+\gamma)<(A+B)+2 \sqrt{A B}$, i.e. condition (25).

\section{B) The model in deviations}

The BRHA housing market model can be reformulated in deviations from the FSS via a straightforward change of variables. As we will see, the model in deviations takes a simpler form than the full model and facilitates its theoretical analysis. Let us introduce the definitions $x_{t}:=P_{t}-P^{*}, y_{t}:=H_{t}-H^{*}, x_{t, t+1}^{e}:=\psi\left(x_{t-1}\right):=\varphi\left(x_{t-1}+P^{*}\right)-P^{*}, i\left(x_{t}\right):=I\left(x_{t}+P^{*}\right)-I\left(P^{*}\right)$, $\rho\left(y_{t}\right):=R\left(y_{t}+H^{*}\right)-R\left(H^{*}\right)$ and $\tilde{\rho}\left(y_{t}\right):=\tilde{R}\left(y_{t}+H^{*}\right)-\tilde{R}\left(H^{*}\right)=\rho\left(y_{t}\right)-\lambda \sigma^{2} y_{t}$. With the above changes of variables, model (18)-(19) can be rewritten as

$$
\begin{aligned}
& x_{t}=f\left(x_{t-1}, y_{t-1}\right):=\frac{\psi\left(x_{t-1}\right)+\tilde{\rho}\left(g\left(x_{t-1}, y_{t-1}\right)\right)}{1+r+\delta}, \\
& y_{t}=g\left(x_{t-1}, y_{t-1}\right):=(1-\delta) y_{t-1}+i\left(x_{t-1}\right),
\end{aligned}
$$

where the aggregate market expectation in deviations is given by

$$
x_{t, t+1}^{e}=\psi\left(x_{t-1}\right):=\varphi\left(x_{t-1}+P^{*}\right)-P^{*}=x_{t-1}+\frac{\not x_{t-1}-\theta v x_{t-1}^{3}}{1+v x_{t-1}^{2}} .
$$

Studying (37)-(38) is equivalent to studying the original model (18)-(19), although in this case the focus is on deviations of the variables from their FSS levels. In particular, the two models have the same Jacobian matrix at their fundamental steady states $(0,0)$ and $\left(P^{*}, H^{*}\right)$, 
respectively.

For the case of isoelastic demand and supply functions, the model in deviations reads

$$
\begin{aligned}
& x_{t}=\frac{\psi\left(x_{t-1}\right)+\left[(r+\delta) P^{*}+\lambda \sigma^{2} H^{*}\right]\left[\left(H^{*}\right)^{m}\left(y_{t}+H^{*}\right)^{-m}-1\right]-\lambda \sigma^{2} y_{t}}{1+r+\delta}, \\
& y_{t}=(1-\delta) y_{t-1}+\delta H^{*}\left[\left(\frac{x_{t-1}+P^{*}}{P^{*}}\right)^{q}-1\right],
\end{aligned}
$$

where $\psi\left(x_{t-1}\right)$ is given by (39).

\section{C) Existence of non-fundamental steady states under strong extrapolation}

For convenience, we use the model in deviations (Appendix B). To prove the existence of non-fundamental steady states, note that $i(0)=0, \quad \rho(0)=\tilde{\rho}(0)=0, \quad \psi(0)=0$, $\tilde{\rho}^{\prime}(0)=\tilde{R}^{\prime}\left(H^{*}\right)(:=-\alpha), \quad i^{\prime}(0)=I^{\prime}\left(P^{*}\right)(:=\beta), \quad i^{\prime}(x)>0, \forall x, \quad \tilde{\rho}^{\prime}(y)<0, \forall y \quad$ and $\psi^{\prime}(0)=\varphi^{\prime}\left(P^{*}\right)=1+\gamma$. A steady-state solution $(\bar{x}, \bar{y})$ of dynamical system (37)-(38) satisfies $(r+\delta) \bar{x}=\frac{\bar{x}-\theta v \bar{x}^{3}}{1+v \bar{x}^{2}}+\tilde{\rho}(\bar{y}), \quad \bar{y}=\frac{i(\bar{x})}{\delta}$

and therefore the steady-state price (deviation) $\bar{x}$ is implicitly defined by

$$
(r+\delta) \bar{x}-\tilde{\rho}\left(\frac{i(\bar{x})}{\delta}\right)=\frac{\not \bar{x}-\theta v \bar{x}^{3}}{1+\sqrt{x^{2}}}
$$

From our assumptions, the left-hand side of (40), say $Q(x)$, is a strictly increasing function of $x$, satisfying $Q(0)=0$ and $Q^{\prime}(0)=r+\delta+\alpha \beta / \delta:=\gamma_{P}$. The right-hand side, $S(x):=\psi(x)-x$, is a nonlinear S-shaped function, satisfying $S(0)=0, S^{\prime}(0)=\psi^{\prime}(0)-1=\gamma>0$, and going to $+\infty$ (resp. $-\infty)$ as $x \rightarrow-\infty$ (resp. $x \rightarrow+\infty)$. It follows that, besides the FSS $\left(x^{*}, y^{*}\right)=(0,0)$, (at least) two additional steady states must necessarily exist for $\gamma>r+\delta+\alpha \beta / \delta=\gamma_{P}$.

More precisely, by increasing parameter $\gamma$ such that it becomes larger than threshold $\gamma_{P}$, two more non-fundamental steady states are created in a neighborhood of the FSS, say 
$\left(x_{U}, y_{U}\right)$ and $\left(x_{L}, y_{L}\right)$, where $x_{U}>0, y_{U}>0$ and $x_{L}<0, y_{L}<0$. This means that if the market expectation $\varphi(P)$ is set according to (27)-(28), the bifurcation boundary $\gamma=\gamma_{P}(A)$ represents in fact a pitchfork bifurcation curve. Clearly, the price-rent ratio at $\left(x_{U}, y_{U}\right)$, say $\pi^{U}:=P^{U} / R\left(H^{U}\right)$, is larger than $\pi^{*}:=P^{*} / R\left(H^{*}\right) \quad$ (where $P^{U}:=x^{U}+P^{*} \quad$ and $\left.H^{U}:=y^{U}+H^{*}\right)$. Vice versa, the price-rent ratio $\pi^{L}$ at $\left(x_{L}, y_{L}\right)$ is smaller than $\pi^{*}$.

The proof can easily be generalized to the case of switching function (30).

\section{D) Details on linear demand and supply curves}

In the case of a linear demand curve for housing services, namely $D(R)=a_{0}-a R$, with $a_{0}>0, a>0$, market clearing condition (1) yields $R(H)=\alpha_{0}-\hat{\alpha} H \quad$, with $\alpha_{0}:=a_{0} / a>0, \hat{\alpha}:=b / a>0$ and therefore $\tilde{R}(H)=\alpha_{0}-\alpha H$, with $\alpha:=\hat{\alpha}+\lambda \sigma^{2}$. The linear investment function is specified as $I(P):=-\beta_{0}+\beta P$, with $\beta_{0}>0, \beta>0$. Since such a linear investment function is obtained from standard profit-maximization with quadratic costs and is obviously restricted to be a non-negative quantity, the above specification holds for $P>\beta_{0} / \beta$, whereas we would set $I(P)=0$ in the opposite case. However, we can ignore this restriction when we consider the model in deviations.

In this case, the FSS, obtained from the general conditions (9)-(10), reads

$$
P^{*}=\frac{\alpha \beta_{0}+\alpha_{0} \delta}{\delta(r+\delta)+\alpha \beta}, \quad H^{*}=\frac{\alpha_{0} \beta-\beta_{0}(r+\delta)}{\delta(r+\delta)+\alpha \beta} .
$$

We can normalize the FSS in such a way that it remains invariant under changes of slopes $\alpha$ and $\beta$ by redefining the intercept parameters $\alpha_{0}$ and $\beta_{0}$ as $\alpha_{0}=(r+\delta) P^{*}+\alpha H^{*}$ and $\beta_{0}=\beta P^{*}-\delta H^{*} . \tilde{R}(H)$ and $I(P)$ can thus be rewritten as the sum of a steady-state component and a deviation from the steady state, i.e.

$$
\tilde{R}(H)=(r+\delta) P^{*}-\alpha\left(H-H^{*}\right), \quad I(P)=\delta H^{*}+\beta\left(P-P^{*}\right) .
$$


Moreover, $R(H)=(r+\delta) P^{*}-\alpha\left(H-H^{*}\right)+\lambda \sigma^{2} H=(r+\delta) P^{*}-\hat{\alpha}\left(H-H^{*}\right)+\lambda \sigma^{2} H^{*}$.

By plugging (41) into (18)-(19), we obtain the two-dimensional map

$$
\begin{aligned}
& P_{t}=\frac{\varphi\left(P_{t-1}\right)+P^{*}(r+\delta)-\alpha\left[(1-\delta)\left(H_{t-1}-H^{*}\right)+\beta\left(P_{t-1}-P^{*}\right)\right]}{1+r+\delta}, \\
& H_{t}=(1-\delta) H_{t-1}+\delta H^{*}+\beta\left(P_{t-1}-P^{*}\right)
\end{aligned}
$$

where $\varphi\left(P_{t-1}\right)$ is given by (28).

The model can be expressed in deviations from the FSS $\left(P^{*}, H^{*}\right)$ by specializing (37)(38) to the linear case or by subtracting $P^{*}$ and $H^{*}$ from both sides of (42) and (43), respectively, and by setting $x:=P-P^{*}, y:=H-H^{*}$, and $\psi(x)=\varphi\left(x+P^{*}\right)-P^{*}$. This yields

$$
\begin{aligned}
& x_{t}=\frac{\psi\left(x_{t-1}\right)-\alpha\left[(1-\delta) y_{t-1}+\beta x_{t-1}\right]}{1+r+\delta}, \\
& y_{t}=(1-\delta) y_{t-1}+\beta x_{t-1}
\end{aligned}
$$

respectively.

For the sake of consistency between the isoelastic and linear specifications, we impose the condition that the two model versions have the same Jacobian matrix at the FSS. This implies that, given the normalized steady state $\left(P^{*}, H^{*}\right)$ and parameters $\hat{\alpha}$ (or $\alpha$ ) and $\beta$ of the linear version, elasticity parameters $m$ and $q$ of the isoelastic version will be given by

$$
\begin{aligned}
& m=\frac{\hat{\alpha} H^{*}}{(r+\delta) P^{*}+\lambda \sigma^{2} H^{*}}=\frac{\left(\alpha-\lambda \sigma^{2}\right) H^{*}}{(r+\delta) P^{*}+\lambda \sigma^{2} H^{*}} \text { and } q=\frac{\beta P^{*}}{\delta H^{*}}, \text { or, given } m \text { and } q, \text { we have } \\
& \hat{\alpha}=m \frac{(r+\delta) P^{*}+\lambda \sigma^{2} H^{*}}{H^{*}}, \alpha=m \frac{(r+\delta) P^{*}}{H^{*}}+(m+1) \lambda \sigma^{2} \text { and } \beta=\frac{q \delta H^{*}}{P^{*}} .
\end{aligned}
$$




\begin{tabular}{|l|l|}
\hline data frequency & $K=4$ \\
\hline exogenous FSS & $P^{*}=H^{*}=100$ \\
\hline interest rate & $r^{(a)}=2 \%, r:=r^{(a)} / K=0.5 \%$ \\
\hline depreciation rate & $\delta^{(a)}=2 \%, \delta:=\delta^{(a)} / K=0.5 \%$ \\
\hline risk premium & $\xi^{(a)}=2 \%, \xi:=\xi^{(a)} / K=0.5 \%$ \\
\hline extrapolation parameter & $\gamma^{(a)}=60 \%, \gamma:=\gamma^{(a)} / K=15 \%$ \\
\hline regression parameter & $\theta^{(a)}=50 \%, \theta:=\theta^{(a)} / K=12.5 \%$ \\
\hline price volatility (beliefs) & $\sigma^{(a)}=0.04 P^{*}=4, \sigma:=\sigma^{(a)} / \sqrt{K}=2$ \\
\hline $\begin{array}{l}\text { absolute risk aversion coefficient } \\
\text { (computed residually) }\end{array}$ & $\lambda=\frac{\xi^{(a)}}{\sigma^{(a)}} \frac{P^{*}}{H^{*}}=\frac{\xi}{\sigma^{2}} \frac{P^{*}}{H^{*}}=0.00125$ \\
\hline annual s.d. of i.i.d. additive price noise & $\sigma_{P}^{(a)}=0.04 P^{*}$ \\
\hline switching parameters & $v_{L}=v_{U}=\frac{100}{\left(P^{*}\right)^{2}}=0.01, c_{L}=\frac{10000}{\left(P^{*}\right)^{3}}=0.01, c_{U}=0$ \\
\hline demand elasticity & $k=1 / m=0.25$ \\
\hline supply elasticity & $q$ varying in the range $[1,5]$ \\
\hline
\end{tabular}

Table 1: Base parameter setting used in the simulations. 


\section{Figure captions}

Figure 1: Dynamics of the perfect-foresight model. The figure shows a qualitative sketch of the dynamic adjustment process following a positive exogenous shock to the steady state. Left panel: phase plot. Right panels: time plots of house prices (top) and housing stock (bottom).

Figure 2: Stability area of the general backward-looking model. The figure presents the region of local asymptotic stability and bifurcation curves for the case of backward-looking expectations, in the plane of parameters $A:=\alpha \beta$ and $\gamma$. The FSS is LAS below the solid black line. In the gray shaded region, the Jacobian matrix has complex eigenvalues at the FSS. Parameters $r$ and $\delta$ are as in our base selection.

Figure 3: Mimicking the perfect-foresight model. The figure shows the adjustment process of house prices (black line) and housing stock (gray line). Parameters as in Table 1 except $\theta=1, q=0.2, \gamma=0.0005$ (left panel), $\theta=1, q=0.8, \gamma=0.05$ (right panel).

Figure 4: The market impact of speculative and real forces. The figure presents bifurcation diagrams of house prices (left panels) and housing stock (right panels) versus extrapolation parameter $\gamma$ (top panels), supply elasticity at the FSS $q$, proportional to slope $\beta$ (middle panels), and demand elasticity at the FSS $k:=1 / m$, inversely proportional to slope $\alpha$ (bottom panels). Other parameters are as in our base selection, with $q=2$.

Figure 5: Duration of housing bubbles and supply elasticity. The figure depicts time plots of house prices (black line) and housing stocks (gray line) for increasing values of supply elasticity $q$ (from top left to bottom right: $q=1, q=2.5, q=4, q=5$ ). Other parameters are as in our base selection.

Figure 6: Basin of attraction and supply elasticity. The figure presents the basin of attraction (light-gray region) of the upper, locally stable non-fundamental equilibrium (denoted by NFSS) for increasing values of the supply elasticity $q$ (from top left to bottom right: $q=1, q=1.2, q=1.4, q=1.57$ ). Other parameters are as in our base selection. The dark gray region is the basin of attraction of a coexisting attractor (the lower non-fundamental equilibrium, except in the bottom-right panel where the competing attractor is a stable curve). 
The top panels and bottom-left panel also show an orbit starting near the FSS and converging to the bubble steady state. The bottom-right panel shows an orbit starting in the basin of the bubble steady state, and another orbit starting close to the FSS, but converging to the attracting curve.

Figure 7: Robustness of housing market bubbles and supply elasticity. The figure shows time plots of the effects of exogenous i.i.d. normal additive price shocks impinging on the deterministic scenarios depicted in Figure 6. The i.i.d. noise has zero mean and (annual) volatility equal to $1 \%$ of the fundamental price. Initial conditions are near to the upper nonfundamental steady state.

Figure 8: Alternative model specifications and time scales. The figure shows model dynamics under linear specification of demand and supply curves and alternative time scales. Parameters as in Figure 5, with supply elasticity equal to 1 (left panels, pitchfork scenario) and 4 (right panels, NS scenario). Top panels: deterministic model, quarterly time scale. Middle panels: deterministic model, monthly time scale. Bottom panels: noisy model, monthly time scale. The i.i.d. normal additive noise on house prices has zero mean and (annual) volatility equal to $1 \%$ of the fundamental price.

Figure 9: Example 1 of calibrated model dynamics. The figure presents a simulation run under i.i.d. normal additive noise on house prices (with annual volatility equal to $4 \%$ of the fundamental price). Dynamics of house prices and housing stocks (top panel), market impact of regressive expectations (middle panel), and price-rent ratios (bottom panel). Parameters are as in the bottom-left panel of Figure 5.

Figure 10: Example 2 of calibrated model dynamics. The figure presents a second simulation run under i.i.d. normal additive noise on house prices. Dynamics of house prices and housing stocks (top panel), market impact of regressive expectations (middle panel) and price-rent ratios (bottom panel). Parameters are as in Figure 9. 


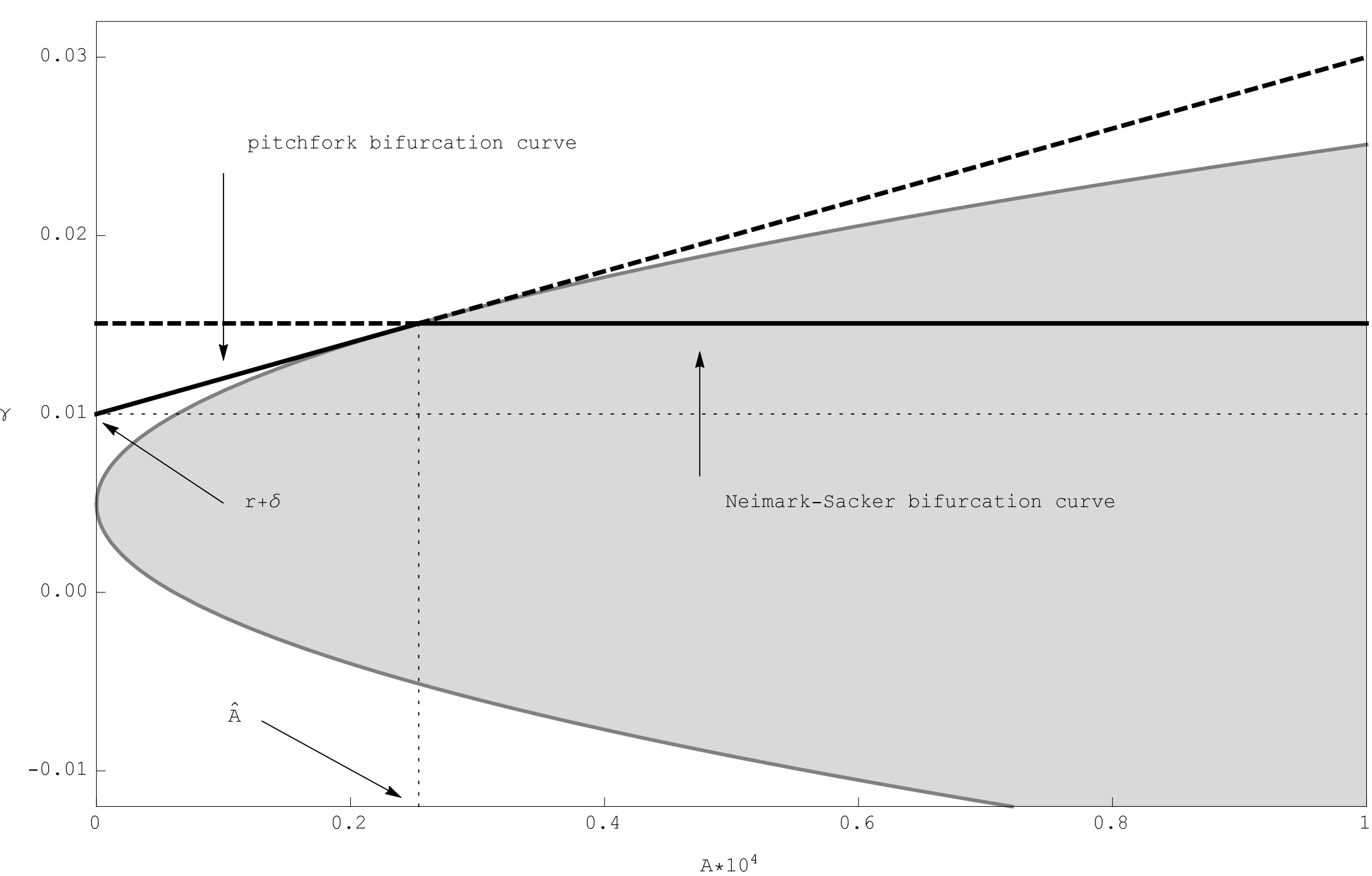

Figure 2 

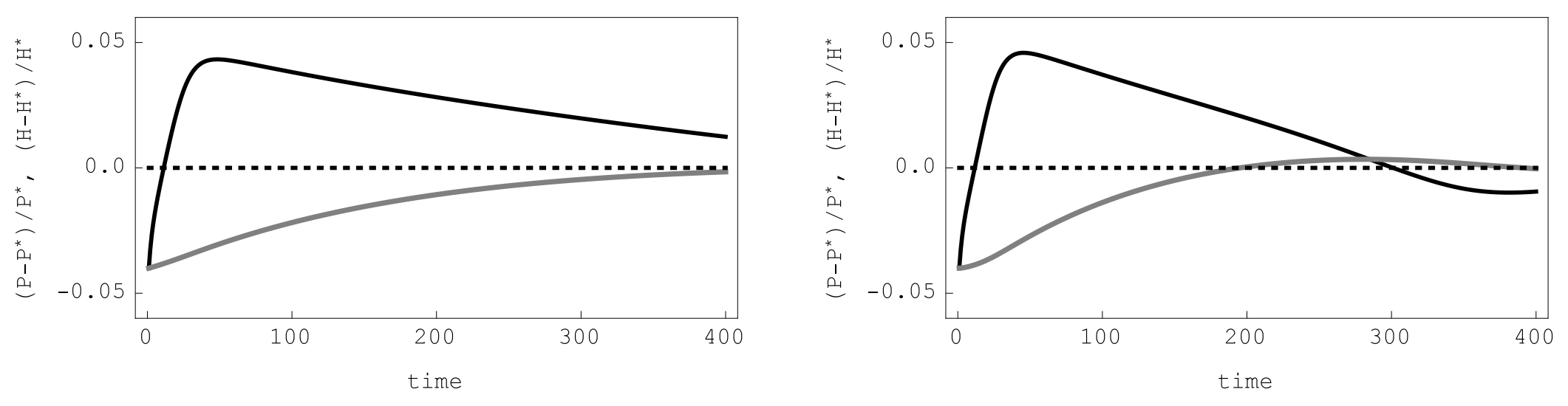

Figure 3

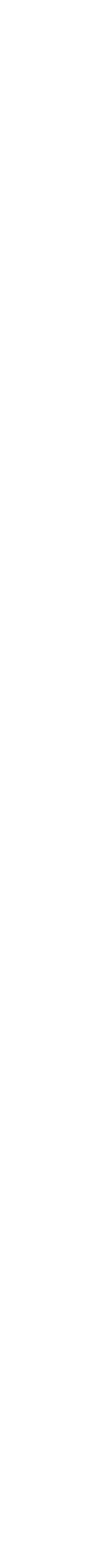

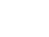

$$
\text { - }
$$

$-1$ 

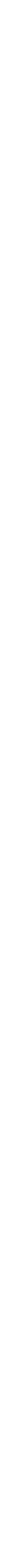

Figure 4

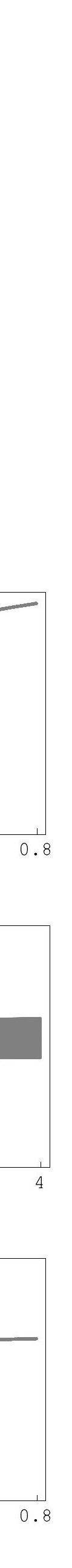



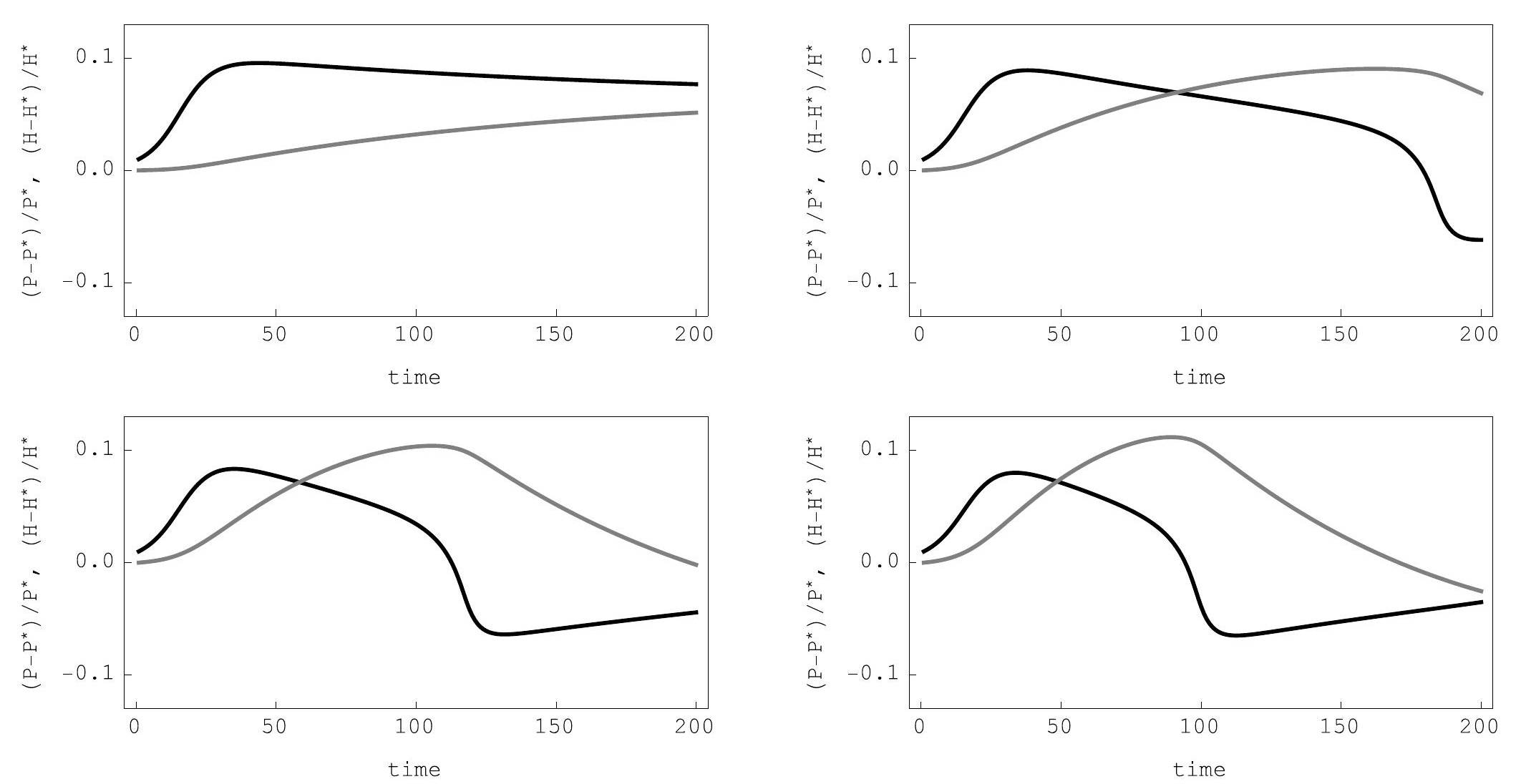

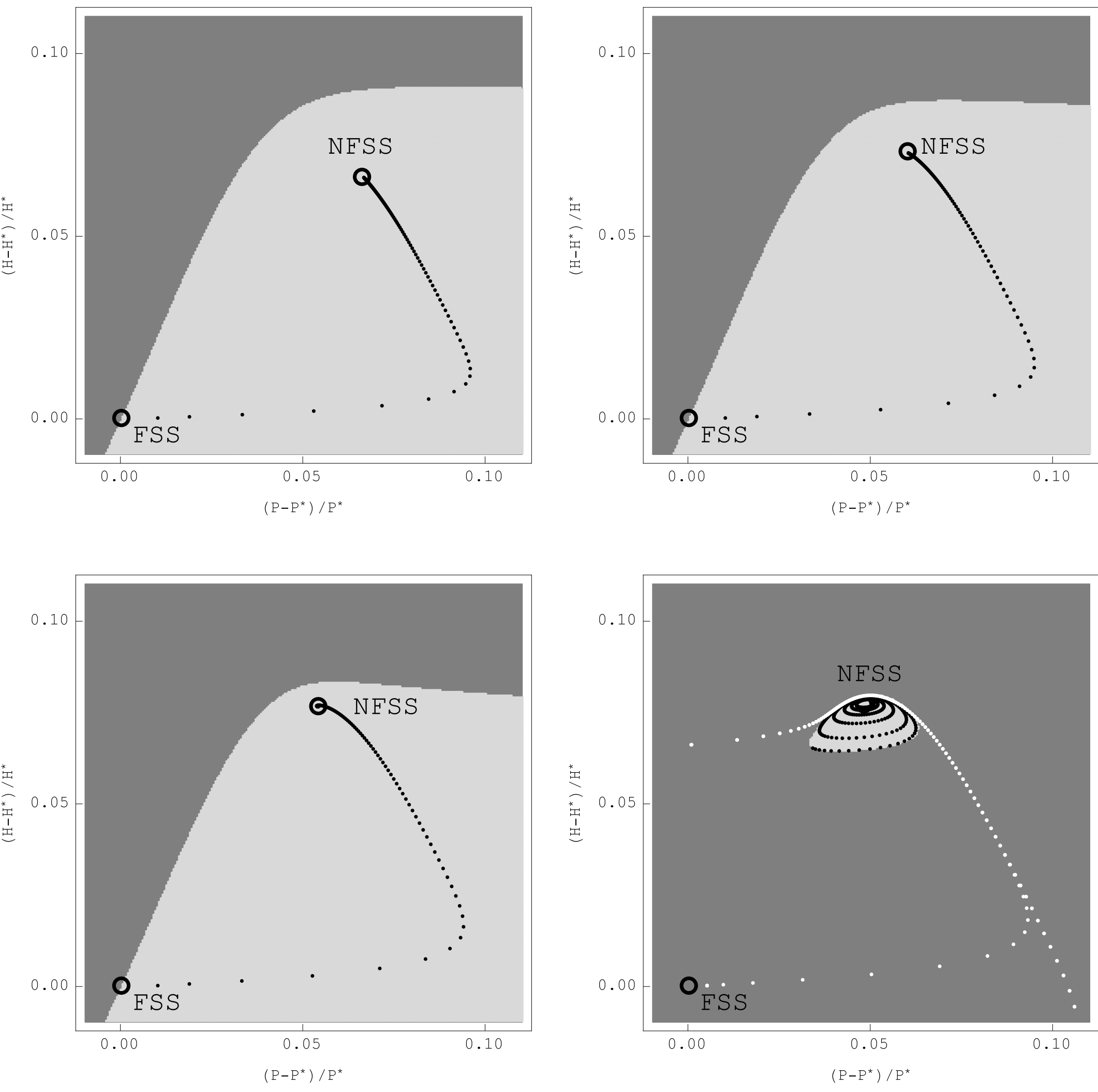
Figure 7
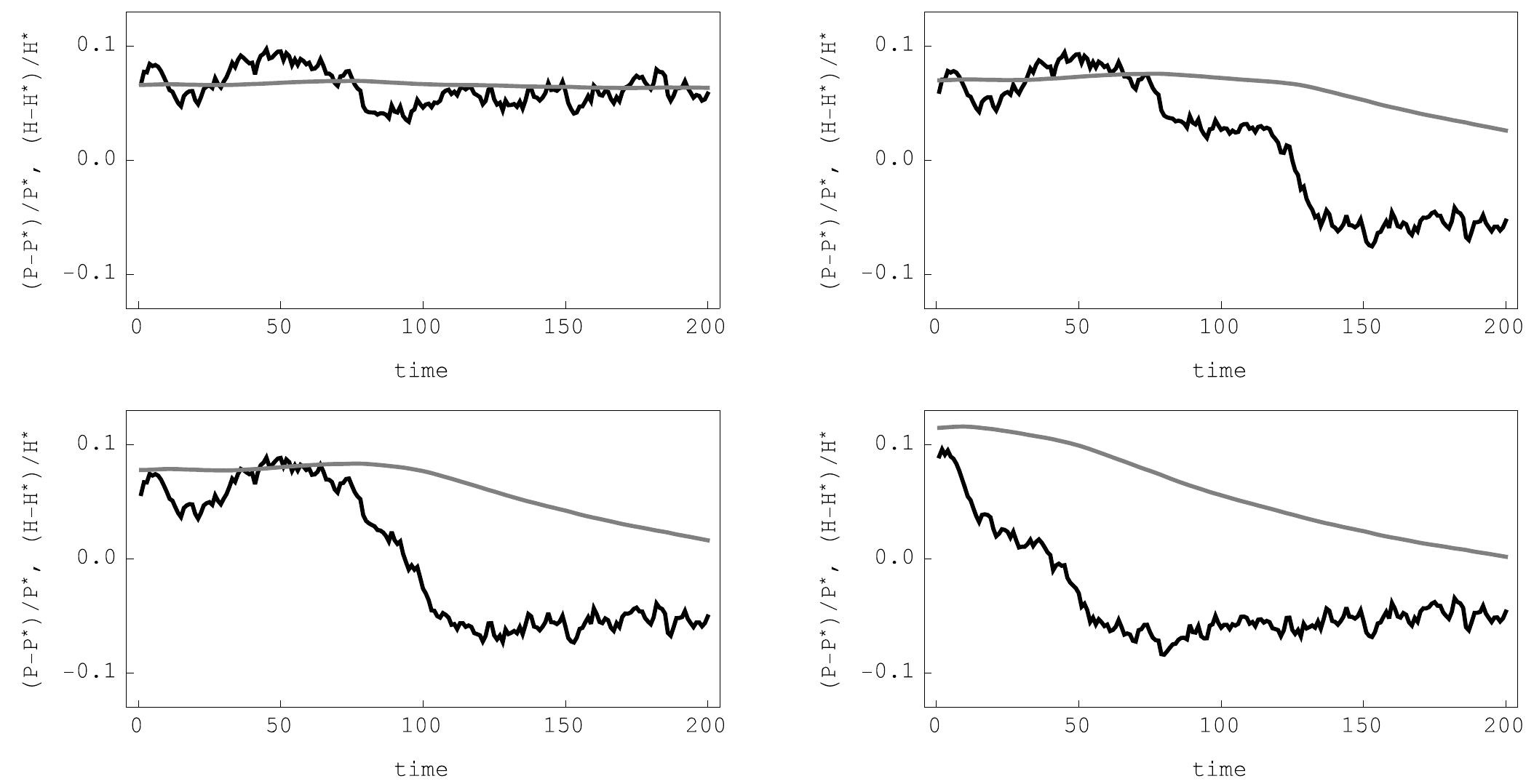

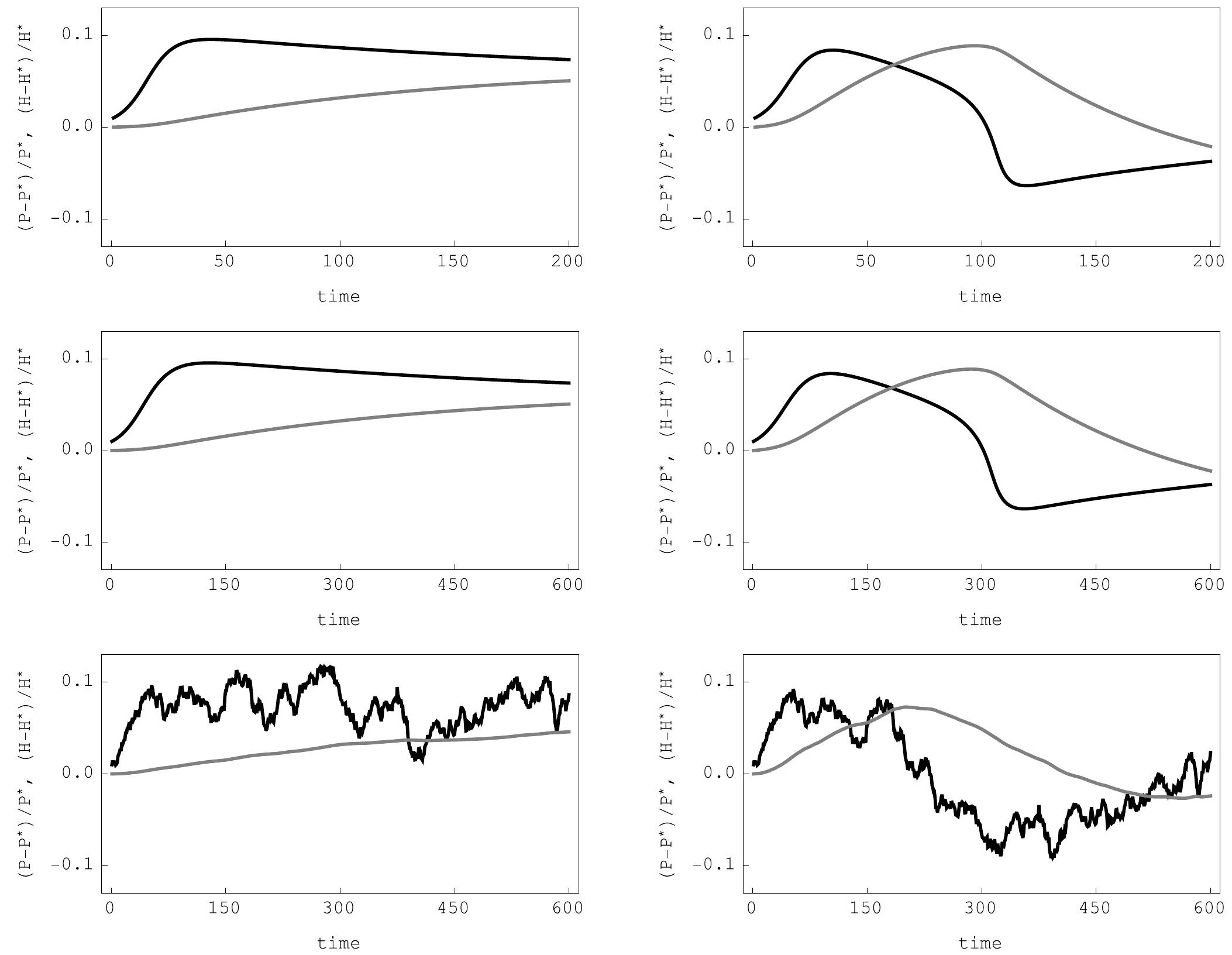

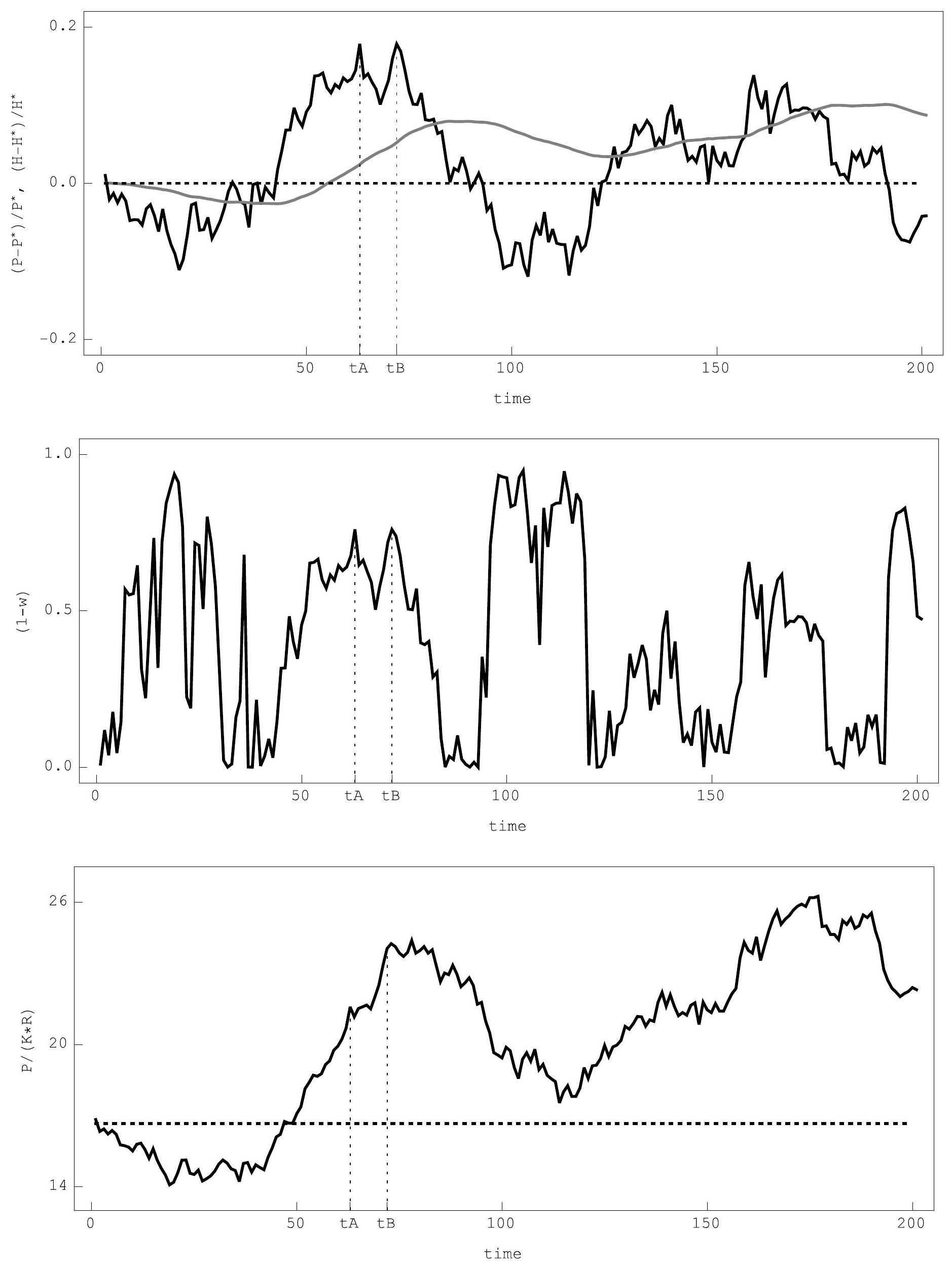

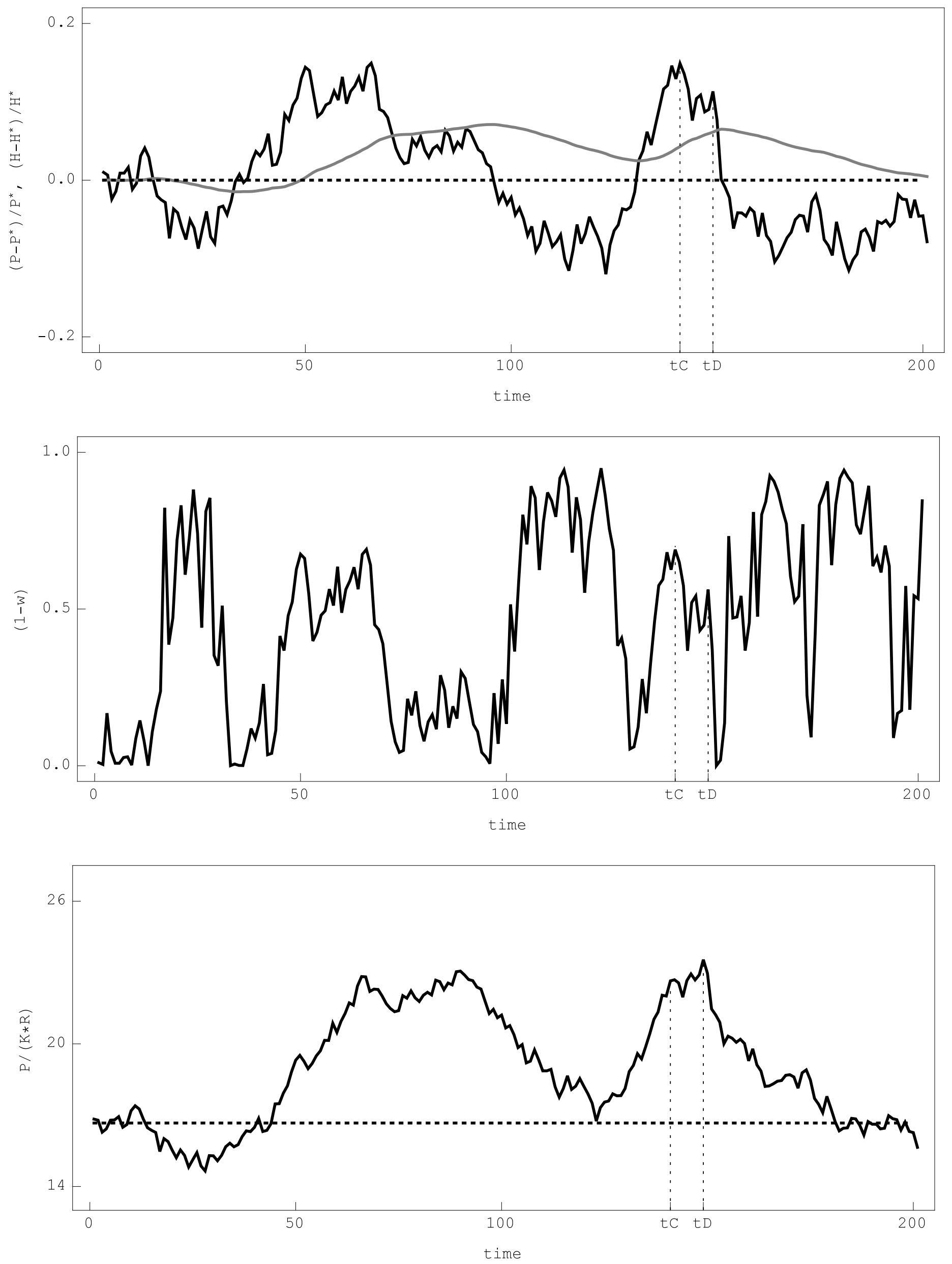